\title{
Multimodule Assembly Strategy for Diverted Total Synthesis and Stereochemical Determination of Laingolide A and Laingolide
}

Chengsen Cui ${ }^{\perp}$ Yecai Lai, ${ }^{\perp, \dagger}$ and Wei-Min Dai*

Hong Kong Branch of the Southern Marine Science and Engineering Guangdong

Laboratory (Guangzhou) and Laboratory of Advanced Catalysis and Synthesis,

Department of Chemistry, The Hong Kong University of Science and Technology, Clear Water Bay, Kowloon, Hong Kong SAR, P. R. of China

${ }^{\perp}$ These authors contributed equally.

${ }^{\dagger}$ Current address: Baiyunshan Pharmaceutical General Factory, Guangzhou

Baiyunshan Pharmaceutical Holdings Co., Ltd., Guangzhou 510515, P. R. of China

*E-mail: chdai@ust.hk
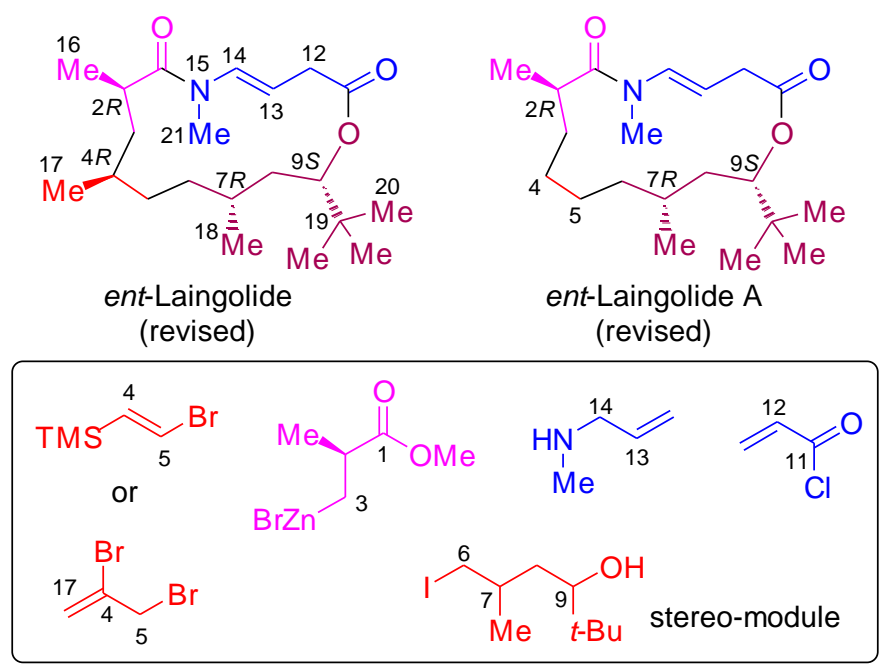


\begin{abstract}
Diverted total synthesis of diastereomers of laingolide A and laingolide has been accomplished and the stereochemistry of both $(E)$-enamide-containing 15-membered macrolides has been assigned. Laingolide $A$ and laingolide have 3 and 4 stereogenic centers, respectively, and only their planar structures were reported. The former has 4 possible diastereomers while the latter has up to 8 diastereomers. A multimodule assembly (MMA) strategy was utilized to disconnect both target molecules into 5 small structural modules among which only one stereochemically varied module (stereo-module) needed to be prepared with other 4 modules available commercially. A sequence of ring-closing metathesis (RCM) and alkene isomerization was used for construction of the macrocyclic skeleton and installation of the $(E)$-enamide moiety. Four each diastereomers of laingolide A and laingolide have been synthesized, leading to assignment of $\left(2 R^{*}, 7 R^{*}, 9 S^{*}\right)$ and $\left(2 R^{*}, 4 R^{*}, 7 R^{*}, 9 S^{*}\right)$ relative stereochemistry for laingolide A and laingolide, respectively. Moreover, according to the $(2 S, 9 R)$ absolute configuration of the congener, laingolide $\mathrm{B}$, the $(2 S, 7 S, 9 R)$ and $(2 S, 4 S, 7 S, 9 R)$ absolute configurations are suggested for laingolide A and laingolide, respectively. The current synthetic efforts reveal, for the first time, that both laingolide A and laingolide possess the 7,9-syn-Me/t-Bu subunit.
\end{abstract}




\section{INTRODUCTION}

Bioactive natural products produced by marine microorganisms are a prolific source of novel molecular entities which serve as lead compounds for drug discovery and development. ${ }^{1-3}$ In particular, marine cyanobacteria produce a variety of bioactive secondary metabolites featuring rich structural types, such as modified peptides, depsipeptides, polyketides, and peptide-polyketide hybrids. ${ }^{4}$ Recent studies provide an in depth understanding on biosynthesis, chemical diversity, biotechnological production, beneficial activities, and clinically-relevant molecular targets of cyanobacterial secondary metabolites. ${ }^{5}$ It is interesting to note that some trans- $N$-methyl enamide-containing macrolides possess a tert-butyl carbinol moiety. ${ }^{6,7}$ This small group of unique macrolides, as depicted in Figure 1, consists of laingolide (1) ${ }^{8}$ laingolide A (2),,${ }^{9,10}$ laingolide B (3), ${ }^{11-13}$ palmyrolide A (4), ${ }^{14-16}$ and madangolide (5). ${ }^{9}$ Moreover, the tert-butyl carbinol-containing polyhydroxylated macrolides, such as amantelides $\mathrm{A} / \mathrm{B},{ }^{17}$ bastimolide $\mathrm{A},{ }^{18}$ and nuiapolide, ${ }^{19}$ and cyclic depsipeptides, such as apratoxins $\mathrm{A} / \mathrm{B} / \mathrm{E}-\mathrm{H}^{20,21}$ and janadolide, ${ }^{22}$ have been isolated from marine cyanobacteria. Palmyrolide A was isolated in 2010 from a marine cyanobacterial assemblage composed of Leptolyngbya $c f$. and Oscillatoria spp. collected from Palmyra Atoll. ${ }^{14}$ The structure of palmyrolide A was originally proposed to feature a 5,7-syn-Me/t-Bu relationship and was later revised to consisting of a 5,7-anti-Me/t-Bu subunit by total synthesis. ${ }^{15 a}$ The absolute configuration at $\mathrm{C} 5$ and $\mathrm{C} 7$ of the revised structure of palmyrolide A (4) was determined as $(5 R, 7 R)$, which is opposite to $(5 S, 7 S)$-anti-Me/t-Bu relationship reported for apratoxin A. ${ }^{23}$ Laingolides $\mathbf{1}-\mathbf{3}$ and madangolide (5) were isolated from different collections of the marine cyanobacterium Lyngbya bouillonii during 1996-2010 and only their planar structures were initially reported without information on all stereogenic centers in $\mathbf{1 - 4} .^{8,9,11}$ In addition, optical rotation data were not available except for laingolide B. ${ }^{11}$ In 2015, Pomey and Phansavath reported the total synthesis of $(2 R, 7 R, 9 R)$-laingolide A (2b in Figure 2) and the corresponding $(Z)$-isomer. ${ }^{10}$ The structure of $(2 R, 7 R, 9 R)$-laingolide A was further confirmed by X-ray crystal structural analysis but its optical rotation data were not reported. We completed diverted total synthesis of two diastereomers of palmyrolide $\mathrm{A}^{15 \mathrm{i}}$ with the revised 5,7-anti-Me/t-Bu subunit and four diastereomers $\mathbf{2 a - 2 d}$ (Figure 2) of laingolide A with both 7,9-anti- and 7,9-syn-Me/t-Bu subunits in $2015 .{ }^{24,25}$ This allowed us to assign the relative configuration of the naturally occurring laingolide $\mathrm{A}$ with a 7,9-syn-Me/t-Bu subunit for the first time among the reported tert-butyl 
carbinol-containing marine natural products. In 2018, we accomplished the total synthesis of two diastereomers of laingolide B and determined the absolute configuration of $(+)$-laingolide $\mathrm{B}$ to be $(2 S, 9 R)$ by comparison of the optical rotation data of both synthetic and natural samples of $3{ }^{13}$ This work not only rendered the structural revision of $\mathbf{3}$ but also enabled assignment of absolute configuration of laingolide (1) and laingolide A (2) on the basis of their common biosynthetic origin. We report here on the total synthesis of all four possible diastereomers $\mathbf{2 a - 2 d}$ of laingolide A (2) and four selected diastereomers of laingolide (1) via a highly efficient "multimodule assembly" (MMA) strategy, leading to assignment of the absolute configuration of laingolide (1) and laingolide A (2). ${ }^{26}$

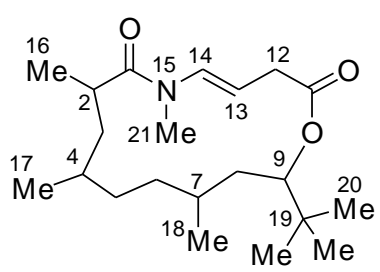

1: Laingolide (proposed)

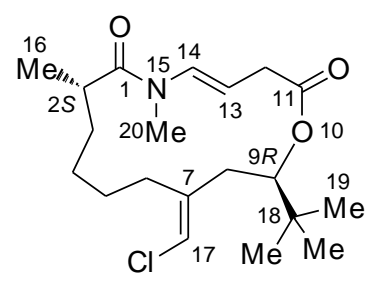

3: (+)-Laingolide B (revised)

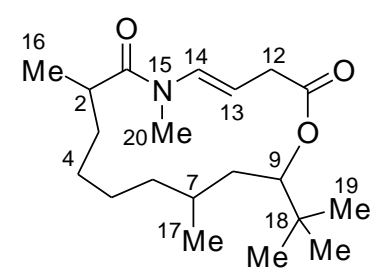

2: Laingolide A (proposed)

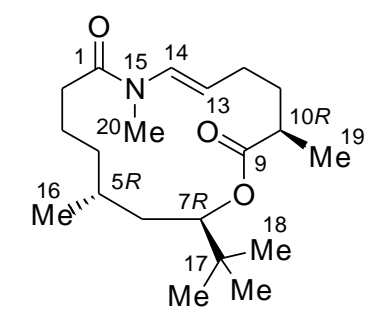

4: (-)-Palmyrolide A (revised)

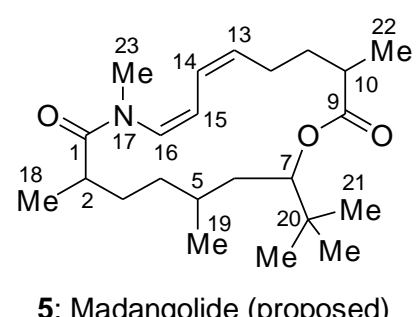

Figure 1. Proposed and revised structures of laingolides 1-3, palmyrolide A (4), and mandangolide (5). 


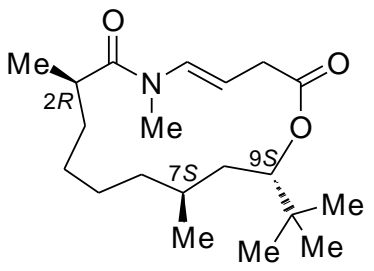

2a: (2R,7S,9S)-Laingolide A $(7,9-a n t i)$

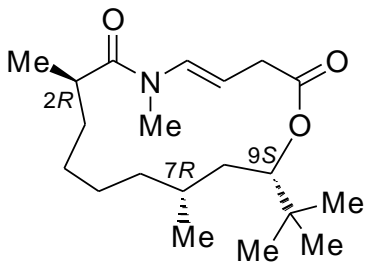

2c: $(2 R, 7 R, 9 S)$-Laingolide $\mathrm{A}$ $(7,9-s y n)$

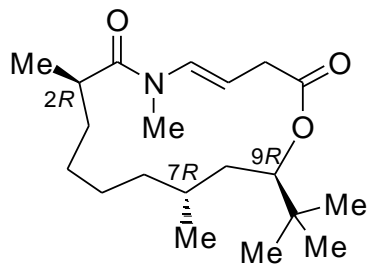

2b: $(2 R, 7 R, 9 R)$-Laingolide $\mathrm{A}$ $(7,9-a n t)$

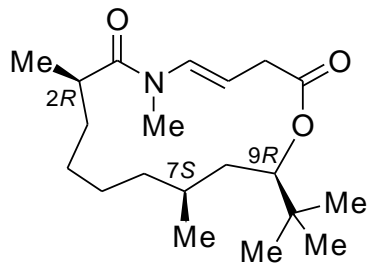

2d: $(2 R, 7 S, 9 R)$-Laingolide A (7,9-syn)

Figure 2. Four diastereomers $\mathbf{2 a}-\mathbf{2 d}$ of laingolide A possessing $2 R$ configuration.

\section{RESULTS AND DISCUSSION}

We begun with our synthetic study on total synthesis of laingolide A which possesses three stereogenic centers at C2, C7, and C9 (Figure 2). If the C2 configuration is randomly selected as $2 R$, there should be four possible diastereomers $\mathbf{2 a}-\mathbf{2 d}$ with variation of stereochemistry at C7 and C9. Compounds $\mathbf{2 a}$ and $\mathbf{2} \mathbf{b}^{10}$ contain a 7,9-anti-Me/t-Bu subunit while compounds $\mathbf{2 c}$ and $\mathbf{2 d}$ feature a 7,9-syn-Me/t-Bu subunit. In order to construct these diastereomers in a speedy manner with minimal longest linear steps (LLS), some general points within the context of "multimodule assembly" (MMA) strategy were considered in exercising retrosynthetic bond disconnection as depicted in Figure 3. These include: (a) selection of structural modules (such as M1-M5) which consist of two orthogonal functionalities on each for modular coupling (MC) reactions and are structurally less complex or even commercially available; (b) design of one module, if possible, which possesses the required structural variation (such as different stereochemistry) so that preparation of these varied modules (such as M5-a to M5-d in Figure 3a) is less labor-demanding; (c) use of minimal functionality manipulation (FM) operations (ideally with $n=0$ ) between two modular coupling reactions for the sake of reducing longest linear steps; and (d) construction of more than one end product through one sequence of reactions (Figure 3c vs. Figure 3b) is advantageous providing that the end products can be separated into pure form. In our total synthesis of (-)-palmyrolide A (4) and (+)-(5S,7S)-palmyrolide A as mentioned 
above, these two target molecules were synthesized via one sequence starting with a racemic and scalemic mixture of the key module, respectively. ${ }^{15 \mathrm{i}}$

A. Structural modules with two orthogonal functionalities

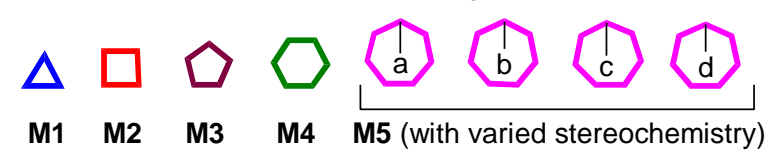

B. A pentamodule assembly synthesis of one product (case 1)
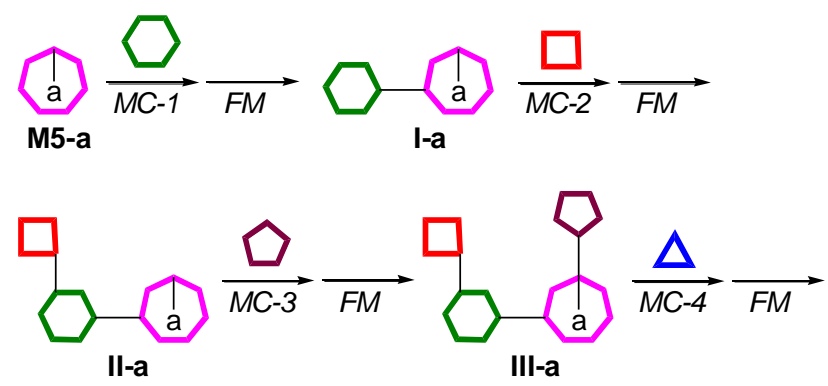

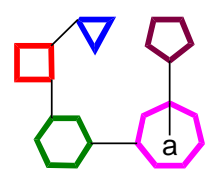

IV-a

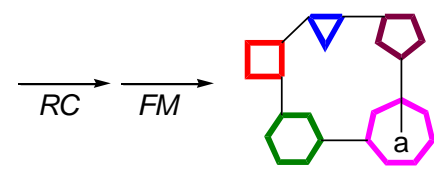

V-a

C. A synthesis of two products in one sequence

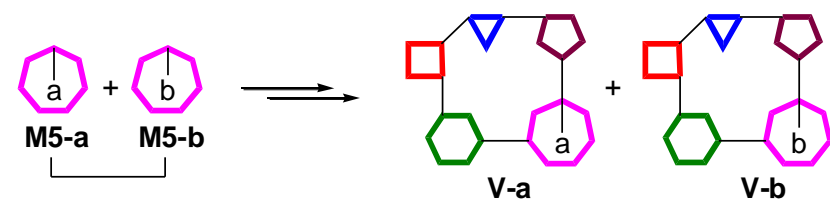

$M C$ : modular coupling (1 operation)

$F M$ : functionality manipulation ( $n$ operations; $n=0,1, \ldots \ldots$ )

$R C$ : ring closure (1 operation)

Figure 3. Schematic illustration of MMA strategy for diverted total synthesis of cyclic natural products and analogues.

According to the MMA strategy mentioned above, our retrosynthetic bond disconnection of laingolide A (2) is depicted in Scheme 1. A sequence of ring-closing metathesis (RCM)-alkene isomerization was envisioned to construct the 15-membered ring at $\mathrm{C} 12-\mathrm{C} 13$ with first formation of a conjugated $\alpha, \beta$-unsaturated lactone. The latter was then thought to undergo $\mathrm{RuH}$-catalyzed double bond isomerization to form the $(E)$-enamide moiety. ${ }^{15 c, f, i}$ We were not sure at the time about the key favorable factor responsible for migration of a conjugated $\alpha, \beta$-unsaturated to a non-conjugated $\beta, \gamma$-unsaturated macrolactone. The $(E)$-enamide moiety in the natural product might provide the driving force, at least to some extent, for facilitating the planned 
transformation. Thus, cleavage of the ester and amide bonds resulted in the $\mathrm{C} 1-\mathrm{C} 9$ acid fragment with two small structural modules, i.e. $N$-allylmethylamine $(\mathbf{8})$ and acryloyl chloride (9). Further bond disconnections at C3-C4 and C5-C6, according to Negishi and $B$-alkyl Suzuki-Miyaura cross-coupling reactions, respectively, traced back the C1-C9 acid fragment to three small structural modules 6, 7, and 10. Both the chiral organozinc compound $\mathbf{7}$ and the stereochemically varied modules (stereo-modules) 10a,b were employed in our total synthesis of (-)-palmyrolide A (4) and (+)-(5S,7S)-palmyrolide A. ${ }^{15 \mathrm{i}}$ The other two stereo-modules 10c,d possessing the 7,9-syn-Me/t-Bu relationship have not been used in the prior work. It is mentioned that (2-bromovinyl)trimethylsilane (6) serves as the precursor of 1,2-dihaloethylene, a linchpin, to connect the two modules 7 and 10. Therefore, among the five modules, the compounds 6-9 are commercially available and only the stereo-modules $\mathbf{1 0 a}-\mathbf{d}$ need to be prepared for total synthesis of laingolide A.

Scheme 1. Retrosynthetic bond disconnection of laingolide A and the requisite five structural modules 6-10 with orthogonal functional groups

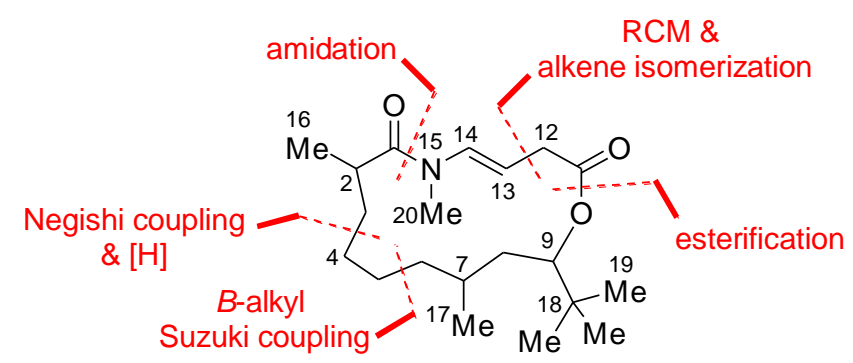

2: Laingolide A (proposed)
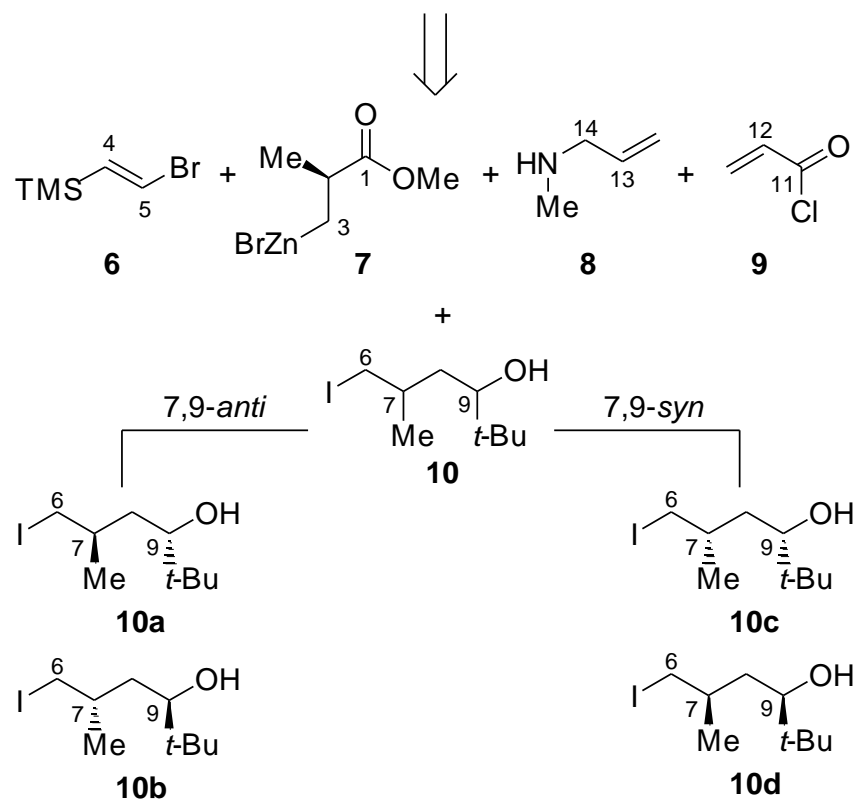
In fact, we tried to use cis- and trans-1,2-dichloroethylene before selecting (2-bromovinyl)trimethylsilane (6) as the linchpin (Scheme 2). ${ }^{27,28}$ Two examples of Suzuki-Miyaura coupling of trans-1,2-dichloroethylene with aryl/vinyl boronic acids were carried out at 45 or $70{ }^{\circ} \mathrm{C} .{ }^{28 \mathrm{a}, \mathrm{b}}$ According to the "9-MeO-9-BBN variant" developed by Fürstner, ${ }^{29}$ a $B$-alkyl Suzuki-Miyaura cross-coupling reaction ${ }^{30}$ was explored for the $\mathrm{C}\left(s p^{3}\right)-\mathrm{C}\left(s p^{2}\right)$ bond formation between the alkyl iodides $r a c-11^{15 \mathrm{i}}$ and 12 and cis- and trans-1,2-dichloroethylene, respectively. Treatment of rac-11 or $\mathbf{1 2}$ with $t$ - $\mathrm{BuLi}$ in the presence of $9-\mathrm{MeO}-9-\mathrm{BBN}$ at $-78^{\circ} \mathrm{C}$ produced the corresponding boron ate complex through initial formation of a new alkyllithium via I-Li exchange and then addition with 9-MeO-9-BBN. After warming the boron ate complex to room temperature, cis- or trans-1,2-dichloroethylene was then added in along with $\mathrm{Pd}(\mathrm{OAc})_{2}$ ( $5 \mathrm{~mol} \%$ ) and Aphos-Y (7.5 mol \%) as the pre-catalyst developed by us. ${ }^{31,32}$ In the total synthesis of natural products, ${ }^{29 b, 33}$ the "9-MeO-9-BBN variant" was usually conducted in THF-DMF mixed solvent by using $\mathrm{Pd}(\mathrm{dppf}) \mathrm{Cl}_{2}-\mathrm{AsPh}_{3}$ as the catalyst system (the Johnson protocol). ${ }^{34}$ Our modified protocol ${ }^{32 b}$ could be performed by using one hemilabile bidentate Aphos-Y ligand in one solvent (THF without adding DMF) under mild basic conditions at room temperature. Unfortunately, all experiments at room temperature or $50^{\circ} \mathrm{C}$ failed to give the desired cross-coupling product $\mathbf{1 3}$ or $\mathbf{1 4}$.

Scheme 2. Attempted modular coupling using cis- and trans-1,2-dichloroethylene ${ }^{35}$
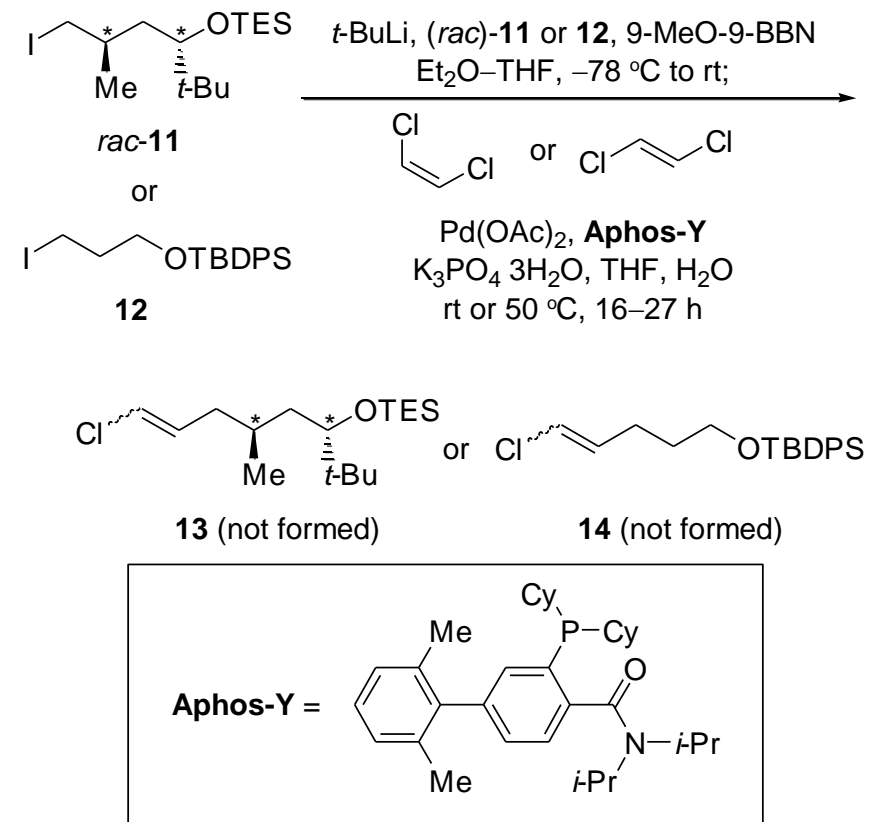
We started synthesis of two products $\mathbf{2 a}$ and $\mathbf{2 b}$ in one sequence as illustrated in Figure $3 \mathrm{c}$. Thus, a diastereomeric mixture of the hydroxy ester 18 possessing 7,9-anti-Me/t-Bu relationship was first assembled (Scheme 3). The known racemic mixture rac-11 $^{15 \mathrm{i}}$ of the TES-protected version of the stereo-modules $\mathbf{1 0 a}$ and $\mathbf{1 0 b}$ was used for the first modular coupling $[M C$-1] with (2-bromovinyl)trimethylsilane (6) which was commercially obtained in $90 \%$ trans isomer. The modular coupling reaction of rac-11 with the vinyl bromide 6 took place in the presence of $\operatorname{Pd}(\mathrm{OAc})_{2}(5 \mathrm{~mol} \%)$ and Aphos-Y (7.5 mol \%) to afford the desired coupling product $r a c-15$ in $90 \%$ yield. The latter was then treated with NIS in $\mathrm{MeCN}$ at $0{ }^{\circ} \mathrm{C}$ to afford the vinyl iodide rac-16 (83\%; $E: Z=10: 1)$ for the next modular coupling [MC-2]. Since the double bond in rac-16 will be saturated at a late stage of the synthesis, the $E / Z$ mixture has no impact on the end products. The commercially available chiral organozinc compound 7 was coupled with the vinyl iodide $r a c-16$ by using $\mathrm{Pd}\left(\mathrm{PPh}_{3}\right)_{2} \mathrm{Cl}_{2}(10 \mathrm{~mol} \%)$ in $\mathrm{THF}\left(40{ }^{\circ} \mathrm{C}, 20 \mathrm{~h}\right)$ to give the ester $\mathbf{1 7}$ in $88 \%$ yield. Also, the same coupling reaction of $\mathbf{7}$ with rac-16 could be performed by using a lower catalyst loading of $\mathrm{Pd}(\mathrm{OAc})_{2}(5 \mathrm{~mol} \%)$ along with Aphos-Y (7.5 mol \%) in THF at room temperature for $20 \mathrm{~h}$ to furnish 17 in $82 \%$ yield. The two 7,9-anti-Me/t-Bu diastereomers of 17, with 10:1 E/Z ratio for the double bond, were inseparable and the mixture was subjected to hydrogenation over $\mathrm{Pd} / \mathrm{C}\left(\mathrm{H}_{2}, \mathrm{EtOH}\right.$ $\mathrm{rt}, \mathbf{4}$ ) to afford, after spontaneous cleavage of the TES ether, the hydroxy ester $\mathbf{1 8}$ in $85 \%$ yield.

With the hydroxy ester $\mathbf{1 8}$ in hand, total synthesis of laingolide A diastereomers $\mathbf{2 a}$ and 2b was executed (Scheme 4). Upon exposure of $\mathbf{1 8}$ to aqueous $\mathrm{NaOH}$ in mixed $\mathrm{THF}-\mathrm{MeOH}-\mathrm{H}_{2} \mathrm{O}(\mathrm{v} / \mathrm{v} / \mathrm{v}=3: 1: 1)$ at room temperature for $7 \mathrm{~h}$, the hydroxy acid $\mathbf{1 9}$ was obtained in $91 \%$ yield as an inseparable mixture of two diastereomers. The modular coupling [MC-3] between 19 and $N$-allylmethylamine (8) was carried out selectively in $83 \%$ yield without protection of the bulky tert-butyl carbinol moiety (Scheme 4). The resultant amides 20a and 20b could be separated over silica gel column and their absolute configuration was confirmed by parallel synthesis starting from a scalemic mixture of 10a and $10 \mathbf{b}$ (vide infra). Thus, esterification of 20a with acryloyl chloride (9) $[M C-4]$ took place in the presence of $i$ - $\operatorname{Pr}_{2} \mathrm{NEt}-\mathrm{DMAP}$ to afford the seco diene $21 \mathrm{a}$ ( $85 \%$ yield) with all five modules assembled in the desired order. 
Scheme 3. Synthesis of the diastereomeric hydroxy ester 18 starting rac-11 ${ }^{35}$

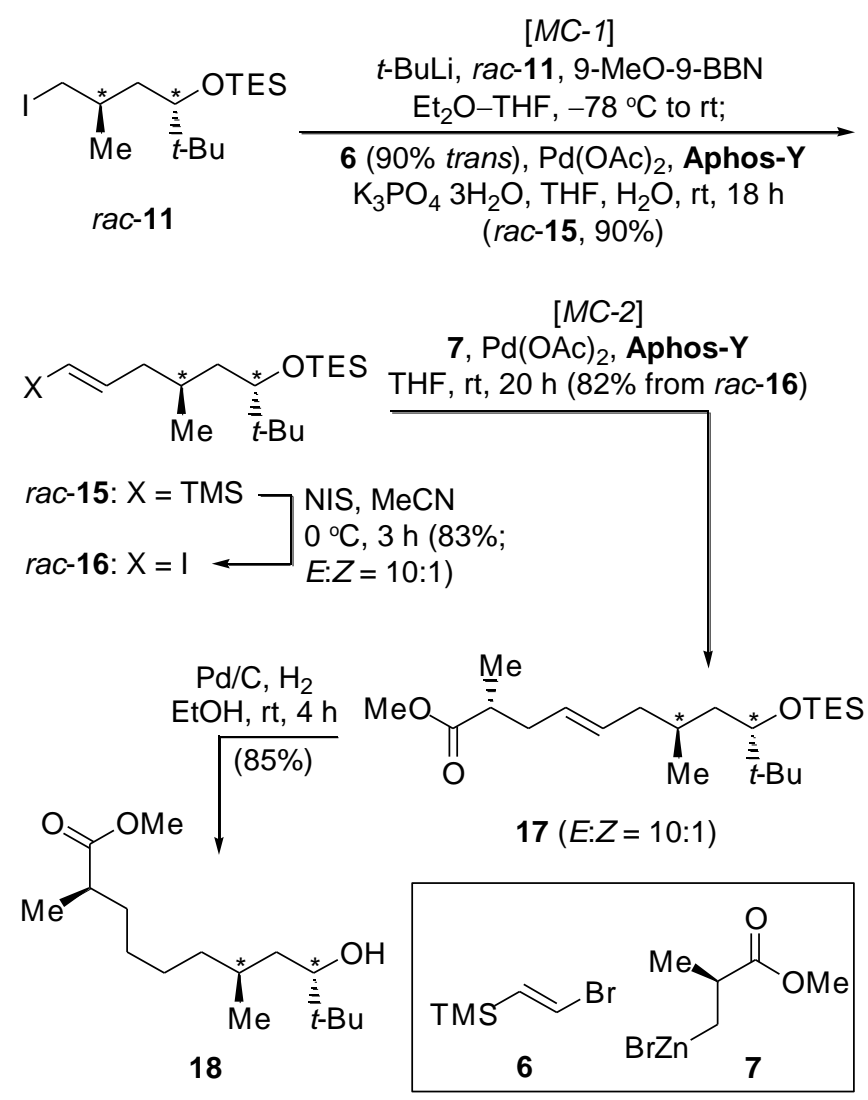

Next, the macrocyclic ring closure $[R C]$ was forged via the ring-closing metathesis (RCM) which was successfully used in our total synthesis of laingolide $\mathrm{B},{ }^{13}$ a congener of laingolide A. The seco diene 21a was treated with 10 mol \% Grubbs 2nd generation (GII) initiator in $\mathrm{ClCH}_{2} \mathrm{CH}_{2} \mathrm{Cl}$ at $80^{\circ} \mathrm{C}$ for $24 \mathrm{~h}$ followed by adding another portion of $10 \mathrm{~mol} \%$ GII initiator and refluxing for another $24 \mathrm{~h}$. Consumption of $21 \mathrm{a}$ was confirmed by TLC analysis of the reaction mixture and the crude RCM product was subjected to alkene isomerization catalyzed by $\mathrm{RuH}\left(\mathrm{PPh}_{3}\right)_{3}(\mathrm{CO}) \mathrm{Cl}(20 \mathrm{~mol} \%)^{36}$ in $\mathrm{PhMe}$ at $110^{\circ} \mathrm{C}$ for $24 \mathrm{~h}$ to furnish laingolide A diastereomer $2 \mathrm{a}$ in $41 \%$ overall yield for 2 steps from 21a. In a similar manner, esterification of $20 \mathbf{b}$ with acryloyl chloride (9) gave the seco diene $\mathbf{2 1 b}$ in $86 \%$ yield. The latter was transformed into laingolide A diastereomer $\mathbf{2} \mathbf{b}^{10}$ (38\% overall yield for 2 steps) via the same RCM and alkene isomerization sequence. The ${ }^{1} \mathrm{H}$ and ${ }^{13} \mathrm{C}$ NMR and specific optical rotation data are listed in Tables $1-3$. The $(E)$-enamide vinyl protons were found at $6.76(\mathrm{~d}, J=13.6 \mathrm{~Hz}$, $\mathrm{NCH}=)$ and $5.22\left(\mathrm{ddd}, J=13.6,9.2,6.0 \mathrm{~Hz},=\mathrm{CHCH}_{2} \mathrm{CO}_{2}\right) \mathrm{ppm}$ for $\mathbf{2 a}$ and at $7.09(\mathrm{~d}, J$ $=14.0 \mathrm{~Hz}, \mathrm{NCH}=)$ and $5.16\left(\mathrm{dt}, J=14.0,7.2 \mathrm{~Hz},=\mathrm{CHCH}_{2} \mathrm{CO}_{2}\right) \mathrm{ppm}$ for $\mathbf{2 b}$, respectively (Table 1). The large coupling constants of 13.6 and $14.0 \mathrm{~Hz}$ between the 
two vinyl protons support the (E)-configuration. To our disappointment, both $\mathbf{2 a}$ and $\mathbf{2 b}$ were not the naturally occurring laingolide $\mathrm{A}$ by comparison of their ${ }^{13} \mathrm{C}$ NMR data listed in Table 2, indicating that laingolide A does not possess the 7,9-anti-Me/t-Bu subunit.

Scheme 4. Total synthesis of laingolide A diastereomers $\mathbf{2 a}$ and $\mathbf{2} \mathbf{b}^{35}$

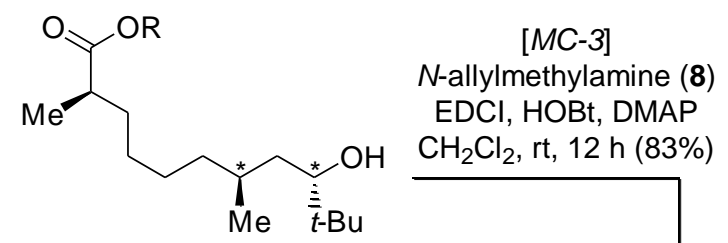

18: $R=M e$ $\mathrm{NaOH}, \mathrm{THF}-\mathrm{MeOH}-\mathrm{H}_{2} \mathrm{O}$ 19: $\mathrm{R}=\mathrm{H} \longleftrightarrow(\mathrm{v}: \mathrm{v}: \mathrm{v}=3: 1: 1), \mathrm{rt}, 7 \mathrm{~h}(91 \%)$<smiles>C=CCN(C)C(=O)[C@H](C)CCCC[C](C)C[C@@H](O)C(C)(C)C</smiles>

20a<smiles>C=CCN(C)C(=O)[C@@H](C)CCCC[C](C)C[C@@H](OC(=O)C=C)C(C)(C)C</smiles>
$21 \mathrm{a}(85 \%)$
[MC-4]<smiles>C=CCN(C)C(=O)C([14CH3])CCCC[C](C)C[C@H](O)C(C)(C)C</smiles>

$20 \mathrm{~b}$ cryloyl chloride (9) $-\mathrm{Pr}_{2} \mathrm{NEt}$, DMAP C to rt, $10 \mathrm{~h}$

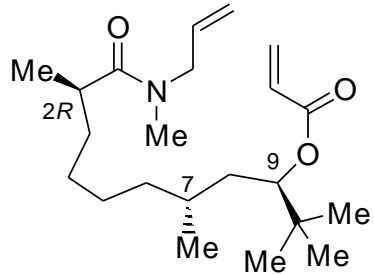

21b $(86 \%)$

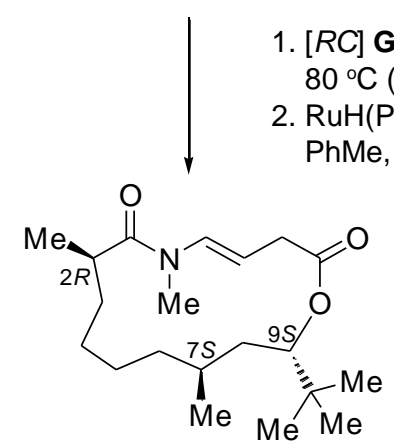

2a $(41 \%$ for 2 steps $)$<smiles>CCOC</smiles>

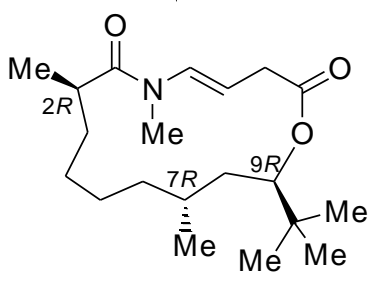

2b (38\% for 2 steps)

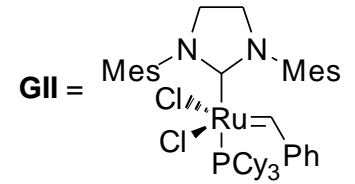


Table 1. Comparison of ${ }^{1} \mathrm{H}$ NMR data of naturally occurring laingolide $\mathrm{A}$ and synthetic diastereomers $\mathbf{2 a}-\mathbf{2 d}$

\begin{tabular}{|c|c|c|c|c|c|c|}
\hline Position $^{a}$ & $2^{b}$ & $2 \mathbf{a}^{c}$ & $2 \mathbf{b}^{c}$ & $2 \mathbf{b}^{d}$ & $2 c^{c,}$ & $2 \mathbf{d}^{c}$ \\
\hline 1 & - & - & - & - & - & - \\
\hline 2 & $2.99, \mathrm{~m}$ & $\begin{array}{l}2.77, \text { sextet } \\
(6.8)\end{array}$ & $\begin{array}{l}2.92, \text { sextet } \\
(6.0)\end{array}$ & $\begin{array}{l}2.91, \text { sextet } \\
(6.5)\end{array}$ & $3.02-2.96, \mathrm{~m}$ & $2.73-2.64, \mathrm{~m}$ \\
\hline $3 a$ & $1.56, \mathrm{~m}$ & $1.75-1.66, \mathrm{~m}$ & $1.67-1.50, \mathrm{~m}$ & $1.68-0.91, \mathrm{~m}$ & $1.64-1.53, \mathrm{~m}$ & $1.50-1.32, \mathrm{~m}$ \\
\hline $3 b$ & $1.40, \mathrm{~m}$ & $1.61-1.54, \mathrm{~m}$ & $1.46-1.37, \mathrm{~m}$ & $1.68-0.91, \mathrm{~m}$ & $1.46-1.37, \mathrm{~m}$ & $1.50-1.32, \mathrm{~m}$ \\
\hline $4 a$ & $1.24, \mathrm{~m}$ & $1.43-1.16, \mathrm{~m}$ & $1.34-1.15, \mathrm{~m}$ & $1.68-0.91, \mathrm{~m}$ & $1.37-1.10, \mathrm{~m}$ & $1.32-1.18, \mathrm{~m}$ \\
\hline $4 b$ & $1.04, \mathrm{~m}$ & $1.43-1.16, \mathrm{~m}$ & $1.10-0.97, \mathrm{~m}$ & $1.68-0.91, \mathrm{~m}$ & $1.10-0.95, \mathrm{~m}$ & $1.32-1.18, \mathrm{~m}$ \\
\hline $5 \mathrm{a}$ & $1.26, \mathrm{~m}$ & $1.43-1.16, \mathrm{~m}$ & $1.34-1.15, \mathrm{~m}$ & $1.68-0.91, \mathrm{~m}$ & $1.37-1.10, \mathrm{~m}$ & $1.32-1.18, \mathrm{~m}$ \\
\hline $5 b$ & $1.12, \mathrm{~m}$ & $1.43-1.16, \mathrm{~m}$ & $1.34-1.15, \mathrm{~m}$ & $1.68-0.91, \mathrm{~m}$ & $1.37-1.10, \mathrm{~m}$ & $1.32-1.18, \mathrm{~m}$ \\
\hline $6 a$ & $1.32, \mathrm{~m}$ & $1.43-1.16, \mathrm{~m}$ & $1.34-1.15, \mathrm{~m}$ & $1.68-0.91, \mathrm{~m}$ & $1.37-1.10, \mathrm{~m}$ & $1.50-1.32, \mathrm{~m}$ \\
\hline $6 b$ & $1.23, \mathrm{~m}$ & $1.43-1.16, \mathrm{~m}$ & $1.34-1.15, \mathrm{~m}$ & $1.68-0.91, \mathrm{~m}$ & $1.37-1.10, \mathrm{~m}$ & $1.32-1.18, \mathrm{~m}$ \\
\hline 7 & $1.17, \mathrm{~m}$ & $1.43-1.16, \mathrm{~m}$ & $1.34-1.15, \mathrm{~m}$ & $1.68-0.91, \mathrm{~m}$ & $1.37-1.10, \mathrm{~m}$ & $1.32-1.18, \mathrm{~m}$ \\
\hline $8 a$ & $1.58, \mathrm{~m}$ & $1.75-1.66, \mathrm{~m}$ & $1.67-1.50, \mathrm{~m}$ & $1.68-0.91, \mathrm{~m}$ & $1.64-1.53, \mathrm{~m}$ & $1.60-1.51, \mathrm{~m}$ \\
\hline $8 b$ & $0.99, \mathrm{~m}$ & $1.43-1.16, \mathrm{~m}$ & $0.90-0.81, \mathrm{~m}$ & $1.68-0.91, \mathrm{~m}$ & $1.10-0.95, \mathrm{~m}$ & $1.18-1.08, \mathrm{~m}$ \\
\hline 9 & $\begin{array}{l}\text { 4.91, dd (11.0, } \\
<1.0)\end{array}$ & $\begin{array}{l}4.95, \mathrm{dd}(10.8, \\
2.0)\end{array}$ & $\begin{array}{l}4.92 \text {, dd (12.0, } \\
1.6)\end{array}$ & $\begin{array}{l}4.99[4.91],{ }^{\mathrm{e}} \mathrm{dd} \\
(12.0,1.6)\end{array}$ & $4.82, \mathrm{~d}(10.4)$ & $4.86, \mathrm{~d}(10.0)$ \\
\hline $10(\mathrm{O})$ & - & - & - & - & - & - \\
\hline 11 & - & - & - & - & - & - \\
\hline $12 \mathrm{a}$ & $\begin{array}{l}3.06 \text {, ddd (12.0, } \\
6.0,1.5)\end{array}$ & $\begin{array}{l}3.13, \mathrm{ABqd} \\
(16.0,5.2)\end{array}$ & $3.09-2.95, \mathrm{~m}$ & $3.04-2.96, \mathrm{~m}$ & $\begin{array}{l}3.07, \text { ABqdd } \\
(12.4,5.6,1.2)\end{array}$ & $\begin{array}{l}3.20, \mathrm{ABqd} \\
(16.0,5.6)\end{array}$ \\
\hline $12 b$ & $\begin{array}{l}2.94, \mathrm{dd}(12.0 \\
10.8)\end{array}$ & $\begin{array}{l}2.98, \mathrm{ABqd} \\
(16.0,9.2)\end{array}$ & $3.09-2.95, \mathrm{~m}$ & $3.04-2.96, \mathrm{~m}$ & $\begin{array}{l}2.94, \mathrm{ABqd} \\
(12.4,10.8)\end{array}$ & $\begin{array}{l}3.07, \mathrm{ABqd} \\
(16.4,8.8)\end{array}$ \\
\hline 13 & $\begin{array}{l}5.18, \text { ddd (14.0, } \\
10.8,6.0)\end{array}$ & $\begin{array}{l}5.22, \text { ddd }(13.6, \\
9.2,6.0)\end{array}$ & $\begin{array}{l}5.15, \mathrm{dt}(14.0, \\
7.2)\end{array}$ & $\begin{array}{l}5.09, \mathrm{dt}(14.1, \\
7.2)\end{array}$ & $\begin{array}{l}5.19, \text { ddd (13.6, } \\
10.0,5.6)\end{array}$ & $\begin{array}{l}5.21 \text {, ddd (14.4, } \\
8.4,6.4)\end{array}$ \\
\hline 14 & $\begin{array}{l}\text { 7.01, dd (14.0, } \\
1.5)\end{array}$ & $6.76, \mathrm{~d}(13.6)$ & 7.09, d (14.0) & $7.08, \mathrm{~d}(14.0)$ & $7.02, \mathrm{~d}(14.0)$ & $6.74, \mathrm{~d}(14.0)$ \\
\hline $15(\mathrm{~N})$ & - & - & - & - & - & - \\
\hline 16 & $\begin{array}{l}1.16,3 \mathrm{H}, \mathrm{d} \\
(6.6)\end{array}$ & $\begin{array}{l}1.15,3 \mathrm{H}, \mathrm{d} \\
(6.4)\end{array}$ & $\begin{array}{l}1.15,3 \mathrm{H}, \mathrm{d} \\
(6.4)\end{array}$ & $\begin{array}{l}1.13,3 \mathrm{H}, \mathrm{d} \\
(6.6)\end{array}$ & $\begin{array}{l}1.16,3 \mathrm{H}, \mathrm{d} \\
(6.8)\end{array}$ & $\begin{array}{l}1.14,3 \mathrm{H}, \mathrm{d} \\
(6.4)\end{array}$ \\
\hline 17 & $\begin{array}{l}0.83,3 \mathrm{H}, \mathrm{d} \\
(7.0)\end{array}$ & $\begin{array}{l}0.90,3 \mathrm{H}, \mathrm{d} \\
(6.8)\end{array}$ & $\begin{array}{l}0.78,3 \mathrm{H}, \mathrm{d} \\
(6.0)\end{array}$ & $\begin{array}{l}0.76,3 \mathrm{H}, \mathrm{d} \\
(6.2)\end{array}$ & $\begin{array}{l}0.84,3 \mathrm{H}, \mathrm{d} \\
(5.6)\end{array}$ & $\begin{array}{l}0.86,3 \mathrm{H}, \mathrm{d} \\
(6.0)\end{array}$ \\
\hline 18 & - & - & - & - & - & - \\
\hline 19 & $0.89,9 \mathrm{H}, \mathrm{s}$ & $0.88,9 \mathrm{H}, \mathrm{s}$ & $0.88,9 \mathrm{H}, \mathrm{s}$ & $0.86,9 \mathrm{H}, \mathrm{s}$ & $0.90,9 \mathrm{H}, \mathrm{s}$ & $0.88,9 \mathrm{H}, \mathrm{s}$ \\
\hline 20 & $3.10,3 \mathrm{H}, \mathrm{s}$ & $3.11,3 \mathrm{H}, \mathrm{s}$ & $3.09,3 \mathrm{H}, \mathrm{s}$ & $3.07,3 \mathrm{H}, \mathrm{s}$ & $3.11,3 \mathrm{H}, \mathrm{s}$ & $3.12,3 \mathrm{H}, \mathrm{s}$ \\
\hline
\end{tabular}

${ }^{a}$ The numbering system shown in Figure 1 is used. ${ }^{b}$ Data are taken by Braekman, Daloze, and co-workers in 1999 in ref. 9 and were recorded in $\mathrm{CDCl}_{3}$ at $600 \mathrm{MHz} .{ }^{c}$ Data were recorded in $\mathrm{CDCl}_{3}$ at $400 \mathrm{MHz}$ with reference to the residual $\mathrm{CHCl}_{3}$ peak at $\delta=7.26 \mathrm{ppm}$ and are listed in the order of chemical shift ( $\mathrm{ppm})$, number of equivalent protons (if $>1$ ), multiplicity, and coupling constants $(\mathrm{Hz})$ in parenthesis. $\mathrm{ABq}$ is designated for the geminal coupling pattern of $\mathrm{CH}_{2}$ at $\mathrm{C} 12 .{ }^{d}$ Data are taken by Pomey and Phansavath in 2015 in ref. 10 and were recorded in $\mathrm{CDCl}_{3}$ at $300 \mathrm{MHz}$ with reference to the residual $\mathrm{CHCl}_{3}$ peak at $\delta=7.26 \mathrm{ppm}$. ${ }^{e}$ The correct chemical shift is $4.91 \mathrm{ppm}$ as shown on the copy of the ${ }^{1} \mathrm{H}$ NMR spectrum in Supporting Information. 
Table 2. Comparison of ${ }^{13} \mathrm{C}$ NMR data of naturally occurring laingolide $\mathrm{A}$ and synthetic diastereomers $\mathbf{2 a}-\mathbf{2 d}$

\begin{tabular}{|c|c|c|c|c|c|c|c|c|c|c|}
\hline Atom $^{a}$ & $2^{b}$ & $2 \mathbf{a}^{c}$ & $\Delta \delta^{d}$ & $2 \mathbf{b}^{c}$ & $\Delta \delta^{d}$ & $2 \mathbf{b}^{e}$ & $2 \mathbf{c}^{c, f}$ & $\Delta \delta^{g}$ & $2 \mathbf{d}^{c}$ & $\Delta \delta^{d}$ \\
\hline 1 & 176.4 & 175.7 & 0.7 & 176.0 & 0.4 & 175.9 & $176.0(176.4)$ & $(0.0)$ & 176.1 & 0.3 \\
\hline 2 & 36.2 & 34.8 & 1.4 & 34.8 & 1.4 & 34.8 & 35.7 (36.2) & $(0.0)$ & 35.0 & 1.2 \\
\hline 3 & 36.6 & 35.1 & 1.5 & 35.1 & 1.5 & 35.1 & $36.1(36.6)$ & $(0.0)$ & 35.7 & 0.9 \\
\hline 4 & 26.2 & 26.9 & -0.7 & 25.5 & 0.7 & 25.5 & $25.6(26.2)$ & $(0.0)$ & 24.3 & 1.9 \\
\hline 5 & 26.8 & 27.0 & -0.2 & 26.0 & 0.8 & 26.0 & $26.2(26.8)$ & $(0.0)$ & 26.1 & 0.7 \\
\hline 6 & 36.8 & 36.5 & 0.3 & 36.8 & 0 & 36.8 & $36.2(36.8)$ & $(0.0)$ & 37.0 & -0.2 \\
\hline 7 & 27.7 & 30.0 & -2.3 & 26.1 & 1.6 & 26.1 & $27.1(27.7)$ & $(0.0)$ & 26.3 & 1.4 \\
\hline 8 & 35.5 & 33.8 & 1.7 & 34.7 & 0.8 & 34.7 & $35.0(35.5)$ & $(0.0)$ & 34.5 & 1.0 \\
\hline 9 & 79.7 & 77.4 & 2.3 & 78.0 & 1.7 & 78.0 & 79.1 (79.7) & $(0.0)$ & 79.9 & -0.2 \\
\hline $10(\mathrm{O})$ & - & - & - & - & - & - & - & - & - & - \\
\hline 11 & 172.5 & 172.8 & -0.3 & 171.6 & 0.9 & 171.6 & $172.0(172.5)$ & $(0.0)$ & 171.4 & 1.1 \\
\hline 12 & 37.6 & 37.1 & 0.5 & 38.0 & -0.4 & 38.0 & 37.1 (37.6) & $(0.0)$ & 38.2 & -0.6 \\
\hline 13 & 105.0 & 103.7 & 1.3 & 103.1 & 1.9 & 103.1 & $104.5(105.0)$ & $(0.0)$ & 106.2 & -1.2 \\
\hline 14 & 133.6 & 132.9 & 0.7 & 133.2 & 0.4 & 133.2 & $133.0(133.6)$ & $(0.0)$ & 132.0 & 1.6 \\
\hline $15(\mathrm{~N})$ & - & - & - & - & - & - & - & - & - & - \\
\hline 16 & 18.5 & 16.7 & 1.8 & 17.4 & 1.1 & 17.4 & $17.9(18.5)$ & $(0.0)$ & 16.0 & 2.5 \\
\hline 17 & 21.2 & 19.6 & 1.6 & 20.3 & 0.9 & 20.3 & 20.7 (21.2) & $(0.0)$ & 18.3 & 2.9 \\
\hline 18 & 35.1 & 33.6 & 1.5 & 33.5 & 1.6 & 33.5 & $34.5(35.1)$ & $(0.0)$ & 33.2 & 1.9 \\
\hline 19 & 26.7 & 26.1 & 0.6 & 26.2 & 0.5 & 26.2 & $26.1(26.7)$ & $(0.0)$ & 24.7 & 2.0 \\
\hline 20 & 31.2 & 30.8 & 0.4 & 30.8 & 0.4 & 30.8 & $30.6(31.2)$ & $(0.0)$ & 31.6 & -0.4 \\
\hline
\end{tabular}

${ }^{a}$ The numbering system shown in Figure 1 is used. ${ }^{b}$ Data are taken by Braekman, Daloze, and co-workers in 1999 in ref. 9 and were recorded in $\mathrm{CDCl}_{3}$ at $150 \mathrm{MHz}{ }^{c}$ Data were recorded in $\mathrm{CDCl}_{3}$ at $100 \mathrm{MHz}$ with reference to the residual $\mathrm{CHCl}_{3}$ peak at $\delta=77.16 \mathrm{ppm} .{ }^{d}$ The difference in chemical shifts $(\Delta \delta$ in ppm) is calculated by $\delta$ (natural) $-\delta$ (synthetic). ${ }^{\mathrm{e}}$ Data are taken by Pomey and Phansavath in 2015 in ref. 10 and were recorded in $\mathrm{CDCl}_{3}$ at $75 \mathrm{MHz}$ with reference to the residual $\mathrm{CHCl}_{3}$ peak at $\delta=77.16$ ppm. ${ }^{f}$ The chemical shifts given in the parentheses are adjusted with reference to the residual $\mathrm{CHCl}_{3}$ peak at $\delta=77.70 \mathrm{ppm} .{ }^{g}$ The difference in chemical shifts ( $\Delta \delta$ in ppm) is calculated by using the adjusted values given in the parenthesis. 
Table 3. Specific optical rotation data $[\alpha]_{\mathrm{D}}$ of laingolide A diastereomers $\mathbf{2 a}-\mathbf{2} \mathbf{d}^{a}$

\begin{tabular}{cccc}
\hline $\mathbf{2 a}$ & $\mathbf{2 b}$ & $\mathbf{2 c}$ & $\mathbf{2 d}^{b}$ \\
\hline$-196.0(c 0.2)$ & $-142.0(c 0.3)$ & $-266.0(c 0.4)$ & $-124.0(c 0.4)$ \\
\hline
\end{tabular}

${ }^{a}$ The data were recorded in $\mathrm{CHCl}_{3}$ at $26{ }^{\circ} \mathrm{C} .{ }^{b}$ Recorded at $25^{\circ} \mathrm{C}$ for the sample $2 \mathrm{~d}$ prepared from the scalemic stereo-module in Scheme 9.

As described above, our pentamodule assembly approach toward laingolide A diastereomers $\mathbf{2} \mathbf{a}$ and $\mathbf{2 b}$ by employing the racemic alkyl iodide rac-11 resulted in an equal amount of two end products. In the case that authentic samples are not available, the structures of the end products are not easy to be correctly assigned. A solution to address this problem could be considered by use of a scalemic mixture of the two stereo-modules. ${ }^{15 \mathrm{i}}$ Therefore, the previously used alkyl iodide $\mathbf{1 1 b}$ of $81 \%$ ee (Scheme 5) was utilized in the same synthetic sequence toward $\mathbf{2 a}$ and $\mathbf{2 b}$ with the latter as the major component. The secondary TBS ether in 11b was selected for easy differentiation from a primary TBS ether during its preparation. ${ }^{15 \mathrm{i}}$ The $B$-alkyl Suzuki-Miyaura cross-coupling reaction of $\mathbf{1 1 b}$ with $\mathbf{6}$ gave the alkenyl TMS product $\mathbf{1 5 b}$, which was transformed into the alkenyl iodide $\mathbf{1 6 b}$ in $88 \%$ overall yield for 2 steps from 11b. The Negishi cross-coupling reaction of $\mathbf{1 6 b}$ with 7 was performed by using $10 \mathrm{~mol} \%$ of $\mathrm{Pd}\left(\mathrm{PPh}_{3}\right)_{2} \mathrm{Cl}_{2}$ in THF (rt, $12 \mathrm{~h}$ ) to afford the ene ester $\mathbf{1 7 b}$ in $80 \%$ yield. Since no hydrogenation of the double bond occurred for $\mathbf{1 7 b}$, the TBS ether in $\mathbf{1 7 b}$ was first removed by treating with $40 \%$ aqueous $\mathrm{HF}$ solution in MeCN. The resultant crude alcohol could be hydrogenated over $\mathrm{Pd} / \mathrm{C}$ in $\mathrm{EtOH}$ (rt, $10 \mathrm{~h}$ ) to furnish the hydroxy ester $\mathbf{1 8 b}$ in $92 \%$ overall yield for 2 steps from $\mathbf{1 7 b}$. After hydrolysis of the ester $\mathbf{1 8 b}$, the acid $19 b$ was subjected to amidation with $N$-allylmethylamine (8) to produce the hydroxy amide $\mathbf{2 0 b}$ in $75 \%$ overall yield for 2 steps from $\mathbf{1 8 b}$. The minor diastereomer $\mathbf{2 0 a}$, originated from the minor enantiomer in $\mathbf{1 1 b}$, was separated out at this stage. Esterification of the alcohol 20b with acryloyl chloride (9) gave the seco diene $\mathbf{2 1 b}$ in $80 \%$ yield. Finally, the same RCM reaction within $\mathbf{2 1 b}$ followed by alkene isomerization as carried out in Scheme 4 furnished laingolide A diastereomer $\mathbf{2 b}$. By comparison of the ${ }^{1} \mathrm{H}$ and ${ }^{13} \mathrm{C}$ NMR data of $\mathbf{2 b}$ synthesized from the scalemic mixture of the alkyl iodide $\mathbf{1 1} \mathbf{b}$ shown in Scheme 5, the structures of $\mathbf{2 a}$ and $\mathbf{2 b}$ constructed from the racemic alkyl iodide $\mathrm{rac}-\mathbf{1 1}$ in Schemes 3 and 4 could be unambiguously assigned. According to the structural inconsistence of both $\mathbf{2} \mathbf{a}$ and $\mathbf{2 b}$ with the natural laingolide 
A (2), it suggests a possibility that the enamide-containing macrolide 2 might possess a 7,9-syn-Me/t-Bu subunit.

Scheme 5. Synthesis of laingolide A diastereomer 2b starting 11b
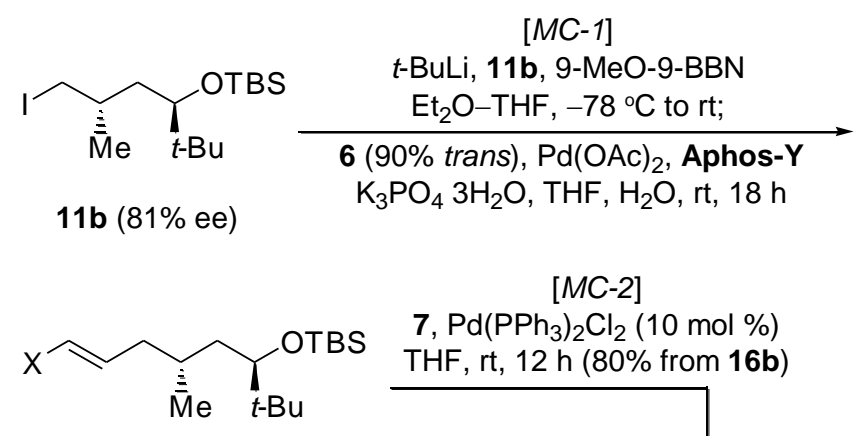

15b: $X=$ TMS $\rightarrow$ NIS, MeCN

16b: $X=1 \longleftarrow \begin{aligned} & 0^{\circ} \mathrm{C}, 3 \mathrm{~h}(88 \% \text { from } \\ & 11 \mathrm{~b} ; E: Z=10: 1)\end{aligned}$

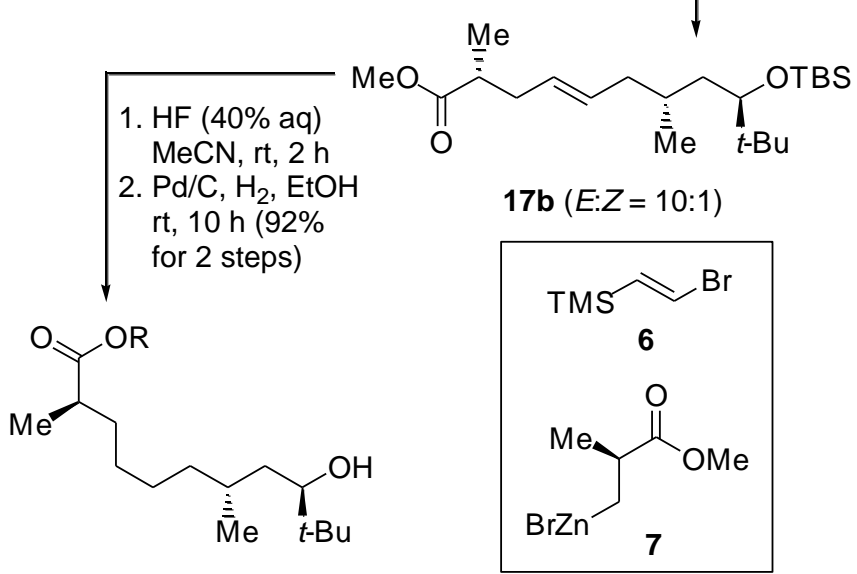

18b: $\mathrm{R}=\mathrm{Me} \longrightarrow \mathrm{NaOH}, \mathrm{THF}-\mathrm{MeOH}-\mathrm{H}_{2} \mathrm{O}$

19b: $\mathrm{R}=\mathrm{H} \Longleftarrow(\mathrm{v}: \mathrm{v}: \mathrm{v}=3: 1: 1), \mathrm{rt}, 10 \mathrm{~h}$

[MC-3]

$\mathrm{N}$-allylmethylamine (8)

EDCl, HOBt, DMAP

$\mathrm{CH}_{2} \mathrm{Cl}_{2}$, rt, $12 \mathrm{~h}$

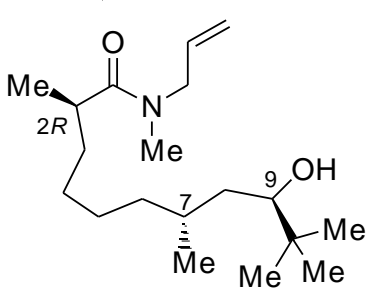

[MC-4]

acryloyl chloride (9) $i-\mathrm{Pr}_{2} \mathrm{NEt}$, DMAP

$\mathrm{CH}_{2} \mathrm{Cl}_{2}, 0^{\circ} \mathrm{C}$ to rt, $10 \mathrm{~h}$

$(80 \%)$

see Scheme 4

20b $(75 \%$ for 2 steps $)$ 
We turned our attention to the synthesis of laingolide A diastereomers $\mathbf{2 c}$ and $\mathbf{2 d}$ as given in Figure 2 by following the "two products in one sequence" approach illustrated in Figure 3c. The two requisite stereo-modules $10 \mathbf{c}$ and $10 \mathbf{d}$ were prepared as the TBS-protected alkyl iodide rac-28 in a racemic form starting from the 3,5-disubstituted dihydrofuran-2-(3H)-one rac-trans-23 (Scheme 6). The known 2-amido arenol $\left(\mathrm{HO}-\mathrm{Ar}^{\mathrm{am}}\right)$ was designed as a stereocontrol moiety during the $\mathrm{SmI}_{2}$-mediated reductive coupling reaction of the methacrylate 22 with trimethylacetaldehyde ( $t$ - $\mathrm{BuCHO})$ to form rac-trans-23 in 95\% with high dr value of 98:2. ${ }^{37}$ The compound rac-trans-23 was transformed into the TES-protected alkyl iodide rac-11 as used in Scheme 3. ${ }^{15 \mathrm{i}}$ For synthesis of the 7,9-syn-Me/t-Bu-containing rac-28, an epimerization was carried out through deprotonation of rac-trans-23 by LDA followed by highly stereoselective protonation of the resultant enolate using 2,6- $(t-\mathrm{Bu})_{2} \mathrm{C}_{6} \mathrm{H}_{3} \mathrm{OH}$ as a bulky proton source to afford rac-cis-24 in $80 \%$ yield with $>98: 2$ dr value. ${ }^{37}$ DIBAL-H reduction of rac-cis-24 gave the diol rac-25 (95\%) which was fully silylated to produce rac-26 in 95\% yield. Selective removal of the primary TBS ether in rac-26 using TBAF-AcOH $(\mathrm{v} / \mathrm{v}=1: 1)$ in THF afforded the alcohol rac-27 (88\%). Treatment of rac-27 with $\mathrm{I}_{2}$, $\mathrm{PPh}_{3}$ and imidazole in THF furnished the alkyl iodide rac-28 in $87 \%$ yield. Similar $B$-alkyl Suzuki-Miyaura cross-coupling reaction between the alkyl iodide $r a c$-28 with 6 under our modified protocol as described in Scheme 3 secured the first modular coupling [MC-1] to give the vinyl TMS product $\mathrm{rac}-\mathbf{2 9}$ in $85 \%$ yield. The TMS group in $r a c-29$ was then exposed to NIS in MeCN to produce the alkenyl iodide rac-30 in $84 \%$ yield with an $E: Z$ ratio of 7:1 originated from the used 6 of $90 \%$ trans form.

The modular coupling [MC-2] between the alkenyl iodide rac-30 and the chiral organozinc compound $\mathbf{7}$ proceeded smoothly to give the ene ester $\mathbf{3 1}$ in $\mathbf{7 5 \%}$ yield as an inseparable mixture of two diastereomers (Scheme 7). Removal of the TBS ether by $40 \%$ aqueous $\mathrm{HF}$ in $\mathrm{MeCN}$ and subsequent hydrogenation over $\mathrm{Pd} / \mathrm{C}$ in $\mathrm{EtOH}$ afforded the hydroxy ester $\mathbf{3 2}$ in $98 \%$ overall yield for the 2 steps. The ester moiety in $\mathbf{3 2}$ was hydrolyzed by treatment with $\mathrm{NaOH}$ in mixed THF-MeOH- $\mathrm{H}_{2} \mathrm{O}(\mathrm{v}: \mathrm{v}: \mathrm{v}=3: 1: 1)$ and the resultant hydroxy acid $\mathbf{3 3}$ was subjected to amidation [MC-3] with $N$-allylmethylamine (8) (EDCI, HOBt, DMAP, $\mathrm{CH}_{2} \mathrm{Cl}_{2}$, rt) to furnish the hydroxy amide 34 in $72 \%$ overall yield for the 2 steps. In contrast to the hydroxy amides $\mathbf{2 0 a} / \mathbf{2 0 b}$ in Scheme 4, the two diastereomers in $\mathbf{3 4}$ could not be separated. 
Scheme 6. Synthesis of the racemic alkenyl iodide rac-30 starting rac-trans-23 ${ }^{35}$

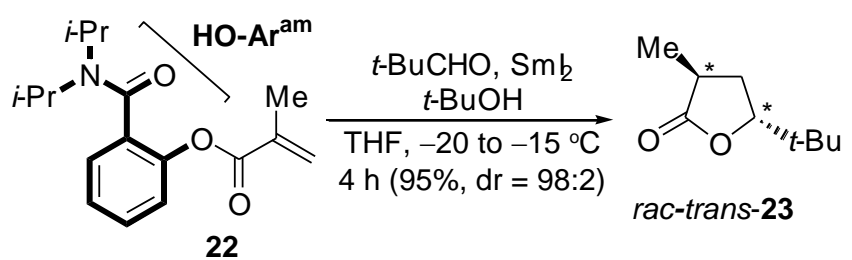

22

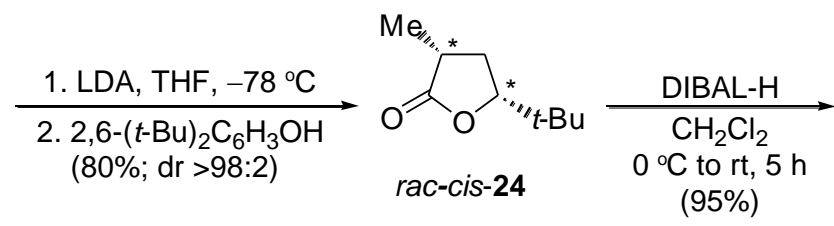

TBSOTf

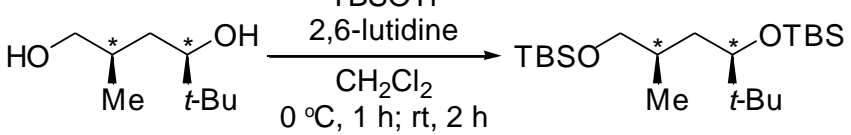

rac-25 (95\%) rac-26

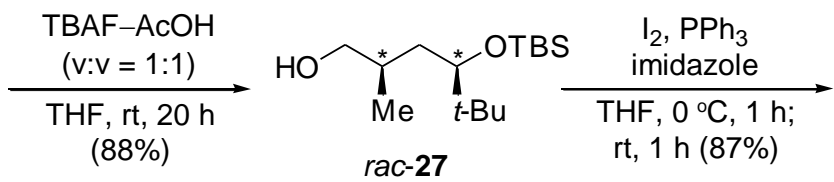

$[M C-1]$

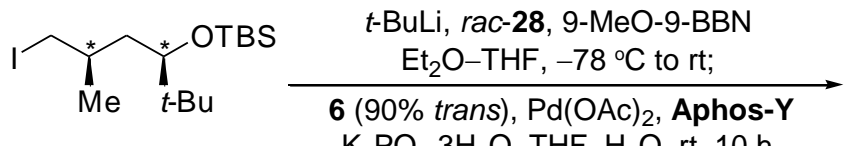

rac-28

$\mathrm{K}_{3} \mathrm{PO}_{4} 3 \mathrm{H}_{2} \mathrm{O}, \mathrm{THF}, \mathrm{H}_{2} \mathrm{O}$, rt, $10 \mathrm{~h}$ (rac-29, 85\%)<smiles></smiles>

$$
{ }_{6}^{\mathrm{TMS}} \overbrace{}^{\mathrm{Br}}
$$

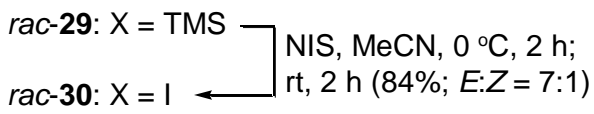

The seco diene 35 was obtained by esterification [MC-4] of the hydroxy amide 34 with acryloyl chloride (9) in 95\% yield. The ring closure $[R C]$ within 35 was performed similarly by treatment with $\mathrm{GII}$ in $\mathrm{ClCH}_{2} \mathrm{CH}_{2} \mathrm{Cl}$ at $80{ }^{\circ} \mathrm{C}$ as described for $\mathbf{2 1 a} / \mathbf{2 1 b}$ in Scheme 4. The resultant two diastereomeric RCM products from 35 could be separated over silica gel column and each RCM product was treated with $\mathrm{RuH}\left(\mathrm{PPh}_{3}\right)_{3}(\mathrm{CO}) \mathrm{Cl}(20$ mol \%) in $\mathrm{PhMe}$ at $110^{\circ} \mathrm{C}$ for $24 \mathrm{~h}$ to isomerize into laingolide A diastereomers $\mathbf{2 c}$ and 2d, respectively, in $50 \%$ overall yield for the 2 steps. Optical rotation data of $[\alpha]_{\mathrm{D}}{ }^{26}$ $-266.0\left(c 0.4, \mathrm{CHCl}_{3}\right)$ for $\mathbf{2 c}$ and $[\alpha]_{\mathrm{D}}{ }^{26}-100.0\left(c 0.4, \mathrm{CHCl}_{3}\right)$ for $2 \mathrm{~d}$ were recorded (Table 3). The two vinyl protons of diastereomer $2 \mathrm{c}$ appear at $7.02(\mathrm{~d}, J=14.0 \mathrm{~Hz})$ and 5.19 (ddd, $J=13.6,10.0,5.6 \mathrm{~Hz}$ ) ppm while those of diastereomer $\mathbf{2 d}$ are found at 6.74 
$(\mathrm{d}, J=14.0 \mathrm{~Hz}$ ) and $5.21(\mathrm{ddd}, J=14.4,8.4,6.4 \mathrm{~Hz}) \mathrm{ppm}$ (Table 1). The large coupling constants of $13.6-14.4 \mathrm{~Hz}$ support the $(E)$-enamide moiety in both $\mathbf{2 c}$ and $\mathbf{2 d}$. It is emphasized that the structures of $\mathbf{2 c}$ and $\mathbf{2 d}$ could only be assigned after parallel synthesis of $\mathbf{2 d}$ starting from the scalemic mixture of $\mathbf{2 3}$ (Scheme 8$).{ }^{15 \mathrm{i}}$

Scheme 7. Synthesis of laingolide A diastereomer $\mathbf{2 c}$ and $\mathbf{2 d}$ from $r a c-30^{35}$
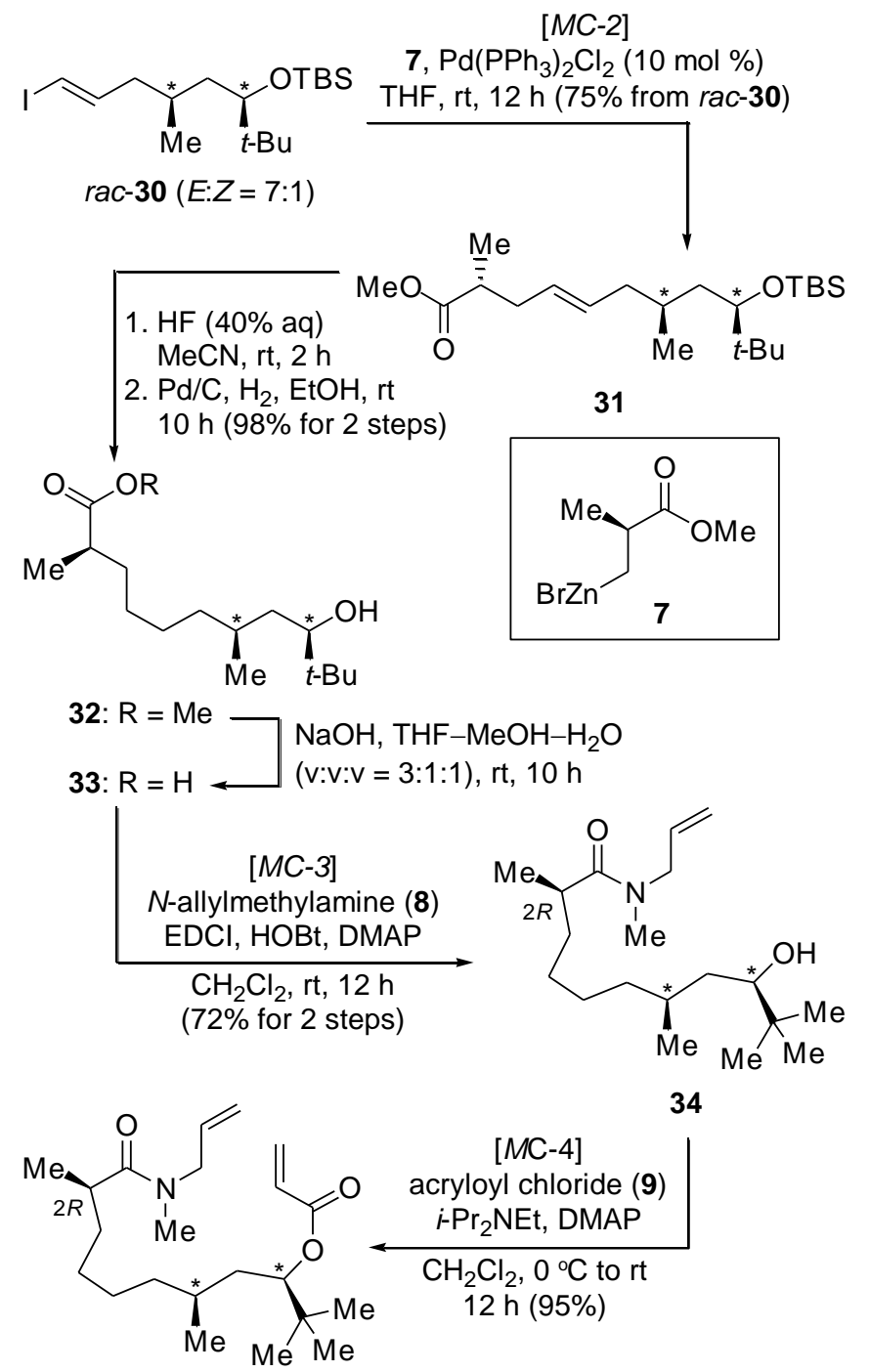

35

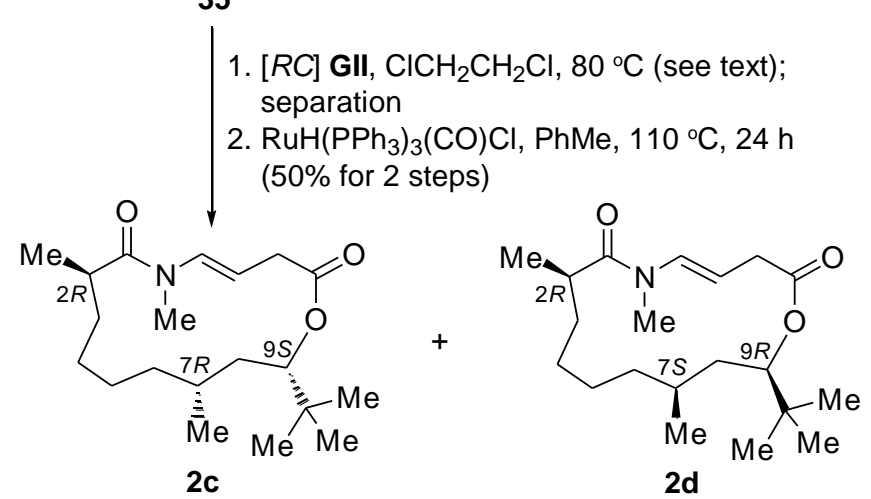


Scheme 8. Synthesis of the scalemic mixture of alkenyl iodide $\mathbf{3 0}$ starting $\mathbf{2 3}$
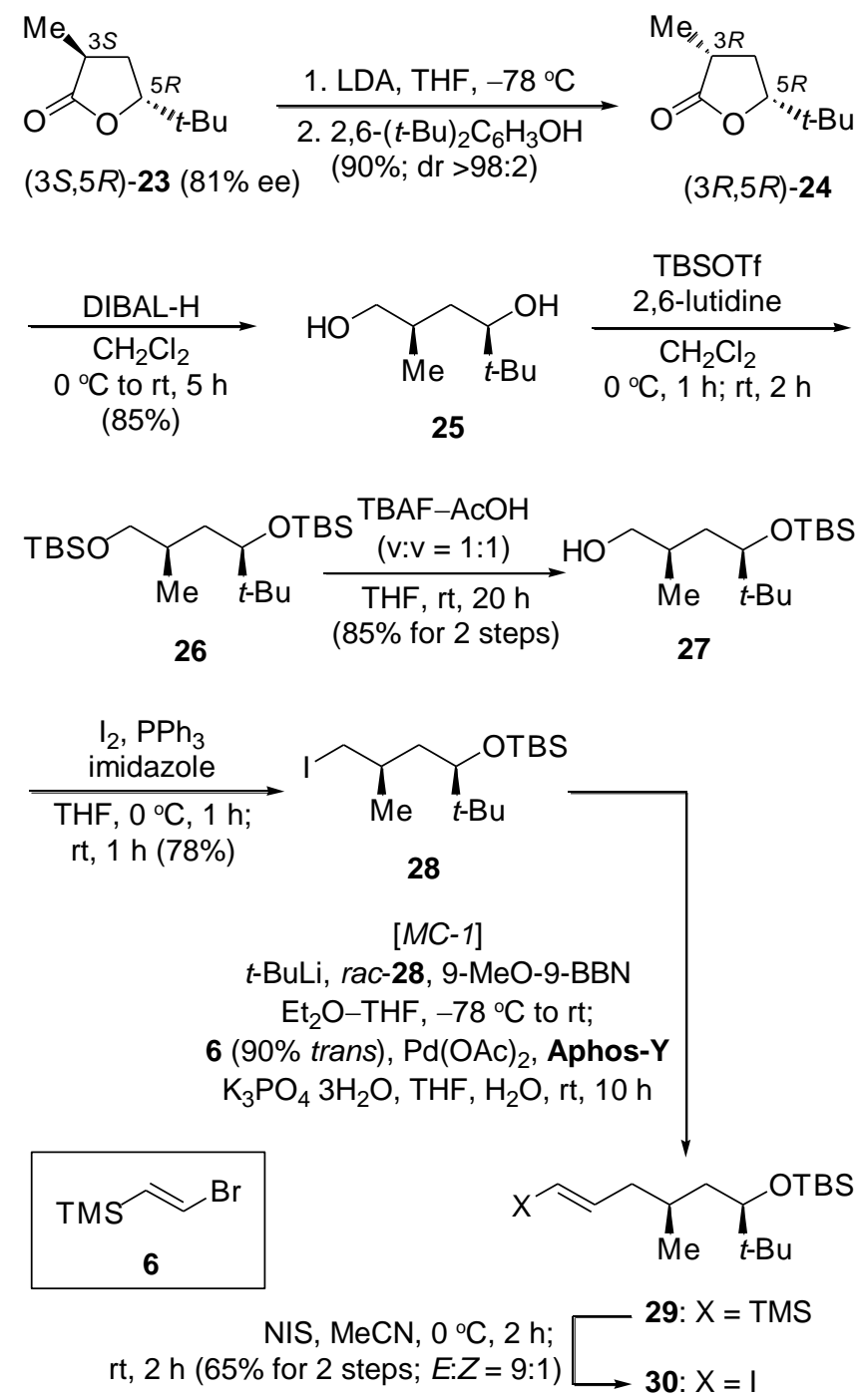

In order to unambiguously assign the structures of $\mathbf{2} \mathbf{c}$ and $\mathbf{2 d}$ obtained from the above described "two products in one sequence" approach, the same synthetic sequence was carried out starting the known $(3 S, 5 R)-\mathbf{2 3}^{15 \mathrm{i}, 38}$ of $81 \%$ ee (Scheme 8$)$. Isomerization of (3S,5R)-23 into $(3 R, 5 R)$-24 was achieved by the deprotonation-protonation operation in $90 \%$ yield and in $>98: 2$ diastereomeric ratio. Reduction of $(3 R, 5 R)-24$ by DIBAL-H gave the diol 25 in $85 \%$ yield. The diol was then converted into the primary alcohol 27 through global silylation of $\mathbf{2 5}$ (TBSOTf, 2,6-lutidine) to form $\mathbf{2 6}$ followed by selective cleavage of the primary TBS ether in $\mathbf{2 6}(\mathrm{TBAF}-\mathrm{AcOH}, \mathrm{v}: \mathrm{v}=1: 1)$. The alcohol 27, obtained in $85 \%$ yield for the 2 steps from 25 , was treated with $\mathrm{I}_{2}, \mathrm{PPh}_{3}$, and imidazole in THF at $0{ }^{\circ} \mathrm{C}$ to room temperature to afford the alkyl iodide 28 in $78 \%$ yield. The first modular coupling between $\mathbf{2 8}$ and $\mathbf{6}$ was performed similarly via the $B$-alkyl Suzuki-Miyaura cross-coupling catalyzed by $\mathrm{Pd}(\mathrm{OAc})_{2}-\mathrm{Aphos}-\mathrm{Y}$ to furnish the 
alkenyl TMS product $\mathbf{2 9}$ which was transformed into the alkenyl iodide $\mathbf{3 0}$ after treatment with NIS in MeCN in 65\% overall yield for the 2 steps. The double bond in 30 was analyzed by ${ }^{1} \mathrm{H}$ NMR spectroscopy to have an $E: Z$ ratio of 9:1 and the double bond will be saturated in further transformation depicted in Scheme 9.

Scheme 9. Synthesis of laingolide A diastereomer 2d
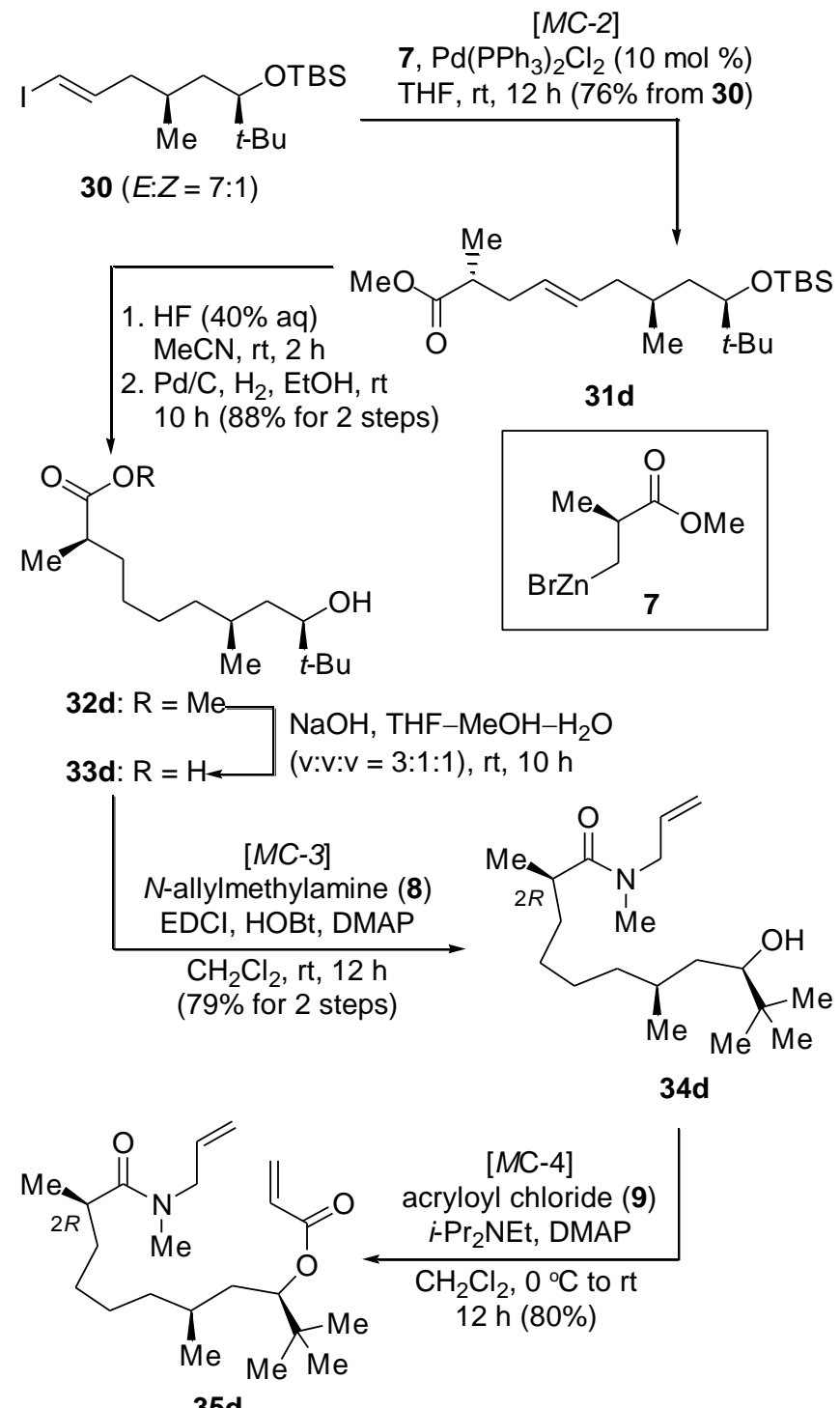
see Scheme 7 (38\% for 2 steps)

2d

The alkenyl iodide $\mathbf{3 0}$ was subjected to Negishi cross-coupling with the chiral organozinc compound 7 to accomplish the second modular coupling [MC-2] and the product 31d was isolated in $76 \%$ yield (Scheme 9). Cleavage of the TBS ether in 31d 
followed by hydrogenation over $\mathrm{Pd} / \mathrm{C}$ in $\mathrm{EtOH}$ gave the hydroxy ester 32d in $88 \%$ overall yield for the 2 steps. The ester 32d was hydrolyzed using aqueous $\mathrm{NaOH}$ in mixed THF-MeOH- $\mathrm{H}_{2} \mathrm{O}$ and the resultant acid 33d was used for modular coupling [MC-3] with $N$-allylmethylamine (8) to furnish the hydroxy amide $\mathbf{3 4 d}$ in $79 \%$ overall yield for the 2 steps. Acylation of the hydroxy group in $\mathbf{3 4 d}$ with acryloyl chloride (9) [MC-4] formed the seco diene 35d (80\%) and the latter was subjected to the RCM-alkene isomerization protocol to furnish laingolide A diastereomer $\mathbf{2 d}$ in $38 \%$ isolated yield for the 2 steps from 34d. Comparison of both ${ }^{1} \mathrm{H}$ and ${ }^{13} \mathrm{C}$ NMR data of $\mathbf{2 d}$ synthesized from the scalemic mixture of (3S,5R)-23 in Schemes 8 and 9 confirmed it identical with the sample of $\mathbf{2 d}$ obtained from racemic alkenyl iodide rac-30 in Scheme 7 (Tables 1 and 2). It was found that a slightly higher optical rotation value $\left\{[\alpha]_{\mathrm{D}}{ }^{25}\right.$ $-124.0\left(c 0.4, \mathrm{CHCl}_{3}\right)$ vs. $\left.[\alpha]_{\mathrm{D}}{ }^{26}-100.0\left(c 0.4, \mathrm{CHCl}_{3}\right)\right\}$ was recorded for $2 \mathbf{d}$ produced in Scheme 9 (Table 3). Therefore, the structure of laingolide A diastereomer $2 \mathbf{c}\left\{[\alpha]_{D}{ }^{26}\right.$ $-266.0\left(c 0.4, \mathrm{CHCl}_{3}\right)$ \} could be unambiguously assigned. We were pleased that the ${ }^{13} \mathrm{C}$ NMR data of our synthesized laingolide A diastereomer $\mathbf{2 c}$ matched perfectly with those of the naturally occurring laingolide $\mathrm{A}$ by setting the internal $\mathrm{CHCl}_{3}$ residue peak at $77.70 \mathrm{ppm}$ instead of $77.16 \mathrm{ppm}$ as listed in Table 2. Our synthetic efforts establish the relative configurational relationship at $\mathrm{C} 5, \mathrm{C} 7$, and $\mathrm{C} 9$ of laingolide $\mathrm{A}$ as $\left(2 R^{*}, 7 R^{*}, 9 S^{*}\right)$ and reveal, for the first time, that the 7,9-syn-Me/t-Bu structural subunit exists in natural product(s) constructed through biosynthetic pathway(s).

With the relative configuration determined for laingolide A, we assumed the same stereochemistry at $\mathrm{C} 2, \mathrm{C} 7$, and $\mathrm{C} 9$ for laingolide due to their common biosynthetic origin. The remaining task was to decode the stereogenic center at $\mathrm{C} 4$ of laingolide. Four laingolide diastereomers $\mathbf{1 a}-\mathbf{1 d}$ possessing $(2 R)$ configuration and 7,9-syn-Me/t-Bu relationship are given in Figure 4. In theory, synthesis of $\mathbf{1 c}$ and $\mathbf{1 d}$ should be sufficient for assignment of the $\mathrm{C} 4$ configuration. In order to avoid unexpected possibility, we decided to synthesize all these four diastereomers according to the retrosynthetic bond disconnection illustrated in Scheme 10. A pentamodule assembly approach was envisioned and a three carbon linchpin, 2,3-dibromopropene (36), was used to construct the C1-C9 hydroxy acid via allylation of an organocopper neucleophile ${ }^{39-41}$ derived from 10c/10d followed by Negishi cross-coupling of 7. In order to quickly access to all four diastereomers $\mathbf{1 a}-\mathbf{1 d}$, we chose the racemic alkyl 
iodide $r a c-\mathbf{2 8}$ used in Scheme 6 as the protected version of $\mathbf{1 0 c / 1 0 d}$ in our first generation of synthesis via the "four products in one sequence" approach (Figure 5). It should be noted that a diastereomer-generating step $\left[F M^{*}\right]$ is involved.<smiles>CC(C)CC[C@@H](C)C[C@@H](OC(=O)C/C=C/N(C)C(=O)C(C)C)C(C)(C)C</smiles>

1a: $(2 R, 4 R, 7 \mathrm{~S}, 9 R)$-Laingolide (7,9-syn

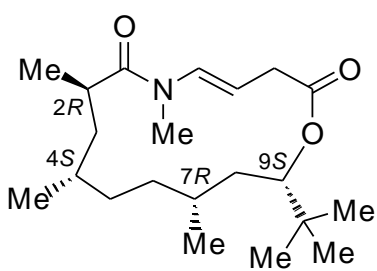

1c: $(2 R, 4 S, 7 R, 9 S)$-Laingolide (7,9-syn)<smiles>CC(C)CC[C@@H](C)C[C@@H](CC(C)C)OC(=O)C/C=C/N(C)C(=O)C(C)C</smiles>

1b: $(2 R, 4 S, 7 S, 9 R)$-Laingolide $(7,9-s y n)$<smiles>CC(C)CC[C@@H](C)C[C@@H](C)C(C)(C)C</smiles>

1d: (2R,4R,7R,9S)-Laingolide (7,9-syn)

Figure 4. Four diastereomers $1 \mathbf{a}-\mathbf{1 d}$ of laingolide possessing $2 R$ configuration and 7,9-syn-Me/t-Bu subunit.

Scheme 10. Retrosynthetic bond disconnection of laingolide and the requisite five structural modules $\mathbf{7 - 9}, \mathbf{1 0 c / 1 0 d}$, and 36 with orthogonal functional groups

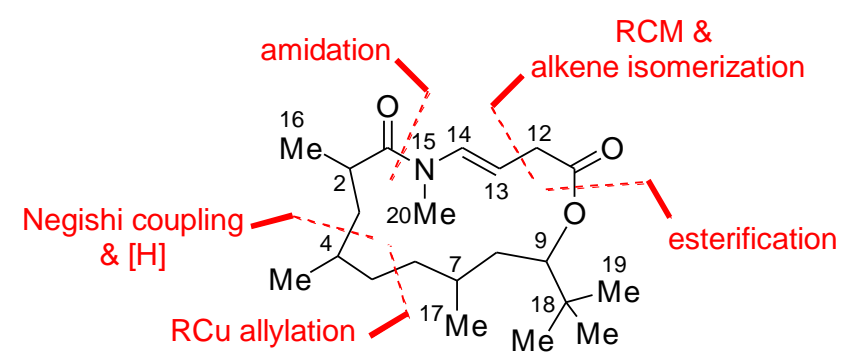

1: Laingolide (proposed)
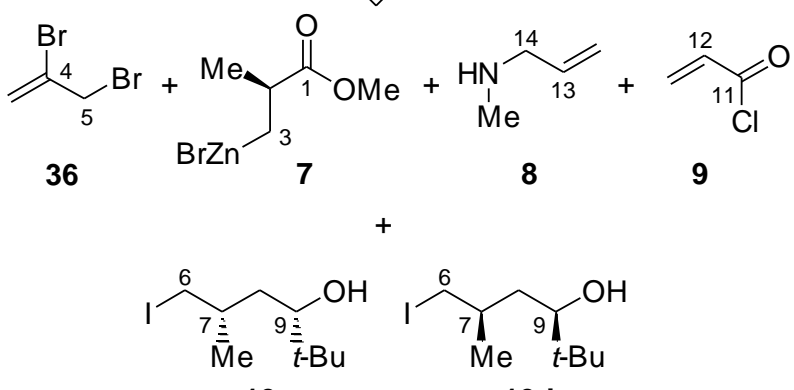

10c 10d 


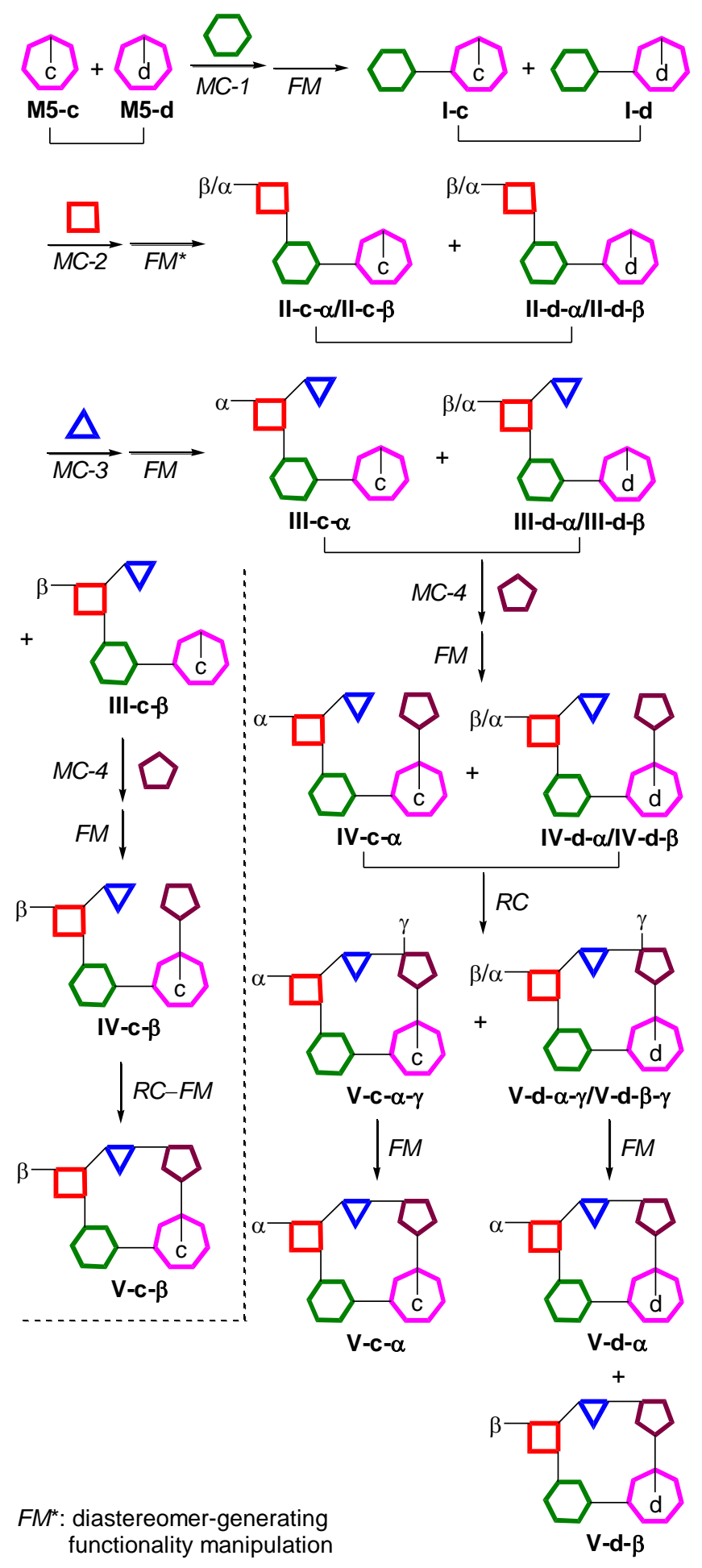

Figure 5. Illustration of a synthesis of four products in one sequence.

We explored the modular coupling [MC-1] between the racemic alkyl iodide rac-28 and 2,3-dibromopropene (36) in the presence of $\mathrm{CuCN}$ (Scheme 11). Treatment of rac-28 with $t$ - $\mathrm{BuLi}$ in $\mathrm{Et}_{2} \mathrm{O}$ at $-78^{\circ} \mathrm{C}$ enabled $\mathrm{I}-\mathrm{Li}$ exchange to form the corresponding alkyl lithium rac-28-Li; the latter underwent nucleophilic allylation with freshly 
distilled 36 in the presence of $10 \mathrm{~mol} \% \mathrm{CuCN}$ at $-78{ }^{\circ} \mathrm{C}$ to afford the desired coupling product $r a c-37$ in $39 \%$ isolated yield along with the alkyl bromide $r a c-28-B r(16 \%)$ and the de-iodination by-product rac-28-H (32\%). The results suggested that the alkyl lithium $\mathrm{rac}$-28-Li demonstrated relatively lower reactivity as compared with the less bulky alkyl lithium, $\mathrm{PMBOCH}_{2} \mathrm{CH}_{2} \mathrm{CH}_{2} \mathrm{Li}$, which reacted with $36(10 \mathrm{~mol} \% \mathrm{CuCN}$, $-78{ }^{\circ} \mathrm{C}$ ) to form the allylation product, $\mathrm{PMBOCH}_{2} \mathrm{CH}_{2} \mathrm{CH}_{2} \mathrm{CH}_{2} \mathrm{C}(\mathrm{Br})=\mathrm{CH}_{2}$, in $67-95 \%$ yields in control experiments (results not shown in Scheme 11). Therefore, rac-28-Li could participate in both $\mathrm{Br}-\mathrm{Li}$ exchange with 36 to give the alkyl bromide rac-28-Br and protonation to form rac-28-H. We were pleased to find that $\mathrm{rac}-\mathbf{2 8}-\mathbf{L i}$ furnished higher yield of the coupling product rac-37 (53\%) when 1 equivalent of $\mathrm{CuCN}$ was used. Under the optimized conditions, $r a c-28$ was subjected to two sequential modular coupling reactions with 36 [MC-1] and 7 [MC-2] to afford the ene ester 38 in $51 \%$ overall yield. Removal of the TBS ether in $\mathbf{3 8}$ by aqueous HF gave the alcohol $\mathbf{3 9}$ in 93\% yield. At this stage, the two diastereomers in both $\mathbf{3 8}$ and $\mathbf{3 9}$ could not be separated. The methylene group at $\mathrm{C} 4$ of $\mathbf{3 9}$ was hydrogenated over $\mathrm{Pd} / \mathrm{C}$ to introduce a new stereogenic center $\left[F M^{*}\right]$, resulting in an inseparable mixture of four diastereomers in $\mathbf{4 0}$ in $95 \%$ yields. Analysis of the ${ }^{1} \mathrm{H}$ NMR spectrum of $\mathbf{4 0}$ revealed some level of diastereoselectivity during the hydrogenation reaction because the ratio of $\alpha$ and $\beta$ configuration at newly generated $\mathrm{C} 4$ stereogenic center is not equal (see also II-c- $\alpha /$ II-c- $\beta$ and II-d- $\alpha /$ II-d- $\beta$ in Figure 5). Hydrolysis of the methyl ester 40 produced the hydroxy acid 41 (98\%) which was subjected to amidation with $\mathrm{N}$-allylmethylamine (8) $[M C-3]$ to furnish the separable hydroxy amide $42 \mathrm{a}$ (12\%) and the mixture 42 (78\%) containing the other three diastereomeric amides. The structure of 42a was assigned by comparing the NMR spectra of laingolide diastereomer 1a with those of laingolide A (vide infra). With the diastereomerically pure 42a, esterification with acryloyl chloride (9) $[M C-4]$ gave the seco diene 43a in $87 \%$ yield. The RCM reaction within 43a $[R C]$ was performed similarly by using $10 \mathrm{~mol} \% \mathrm{GII}$ in $\mathrm{ClCH}_{2} \mathrm{CH}_{2} \mathrm{Cl}$ at $80{ }^{\circ} \mathrm{C}$ for $24 \mathrm{~h}$ followed adding another portion of $10 \mathrm{~mol} \% \mathrm{GII}$ and stirring at $80{ }^{\circ} \mathrm{C}$ for further $24 \mathrm{~h}$. The isolated RCM product 44a was checked by NMR spectroscopy to reveal two similar structures in a ratio of $62: 38$. The vinyl proton at $\mathrm{C} 12$ were found at $5.88(\mathrm{~d}, J=$ $16.0 \mathrm{~Hz})$ and $5.85(\mathrm{~d}, J=15.6 \mathrm{~Hz}) \mathrm{ppm}$ for the major and minor components, respectively. The large coupling constants of 15.6/16.0 Hz suggest both have an (E)-configuration. Moreover, the two components were inseparable over silica gel 
Scheme 11. Synthesis of laingolide diastereomer $\mathbf{1 a}$ from $\mathbf{r a c}-\mathbf{2 8}^{35}$

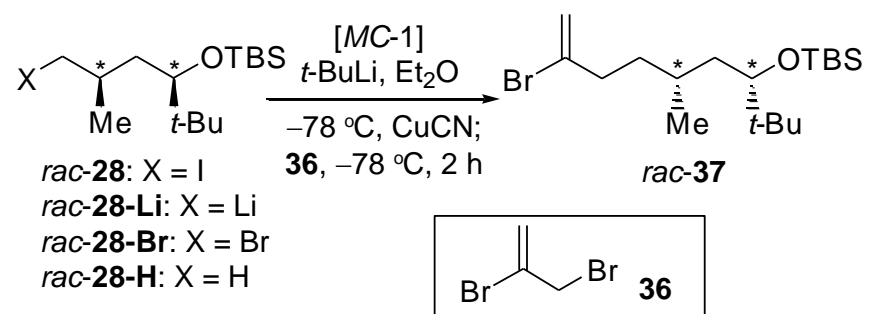

[MC-2]

7, $\mathrm{Pd}\left(\mathrm{PPh}_{3}\right)_{2} \mathrm{Cl}_{2}$

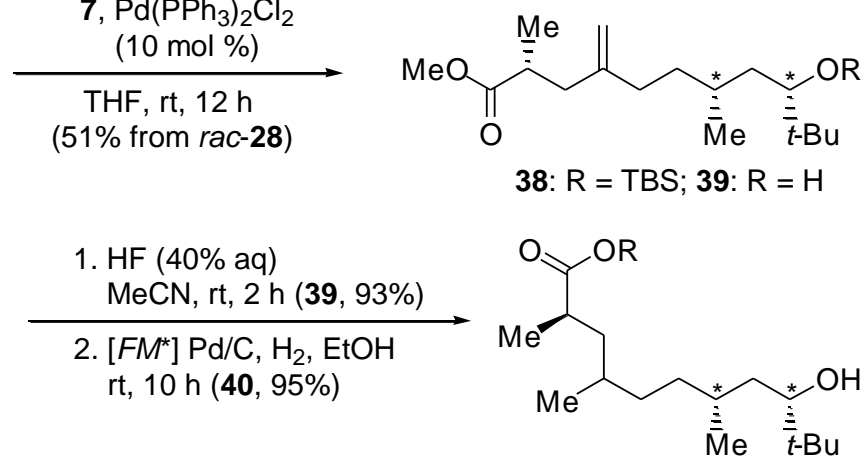

$\begin{array}{r}\mathrm{NaOH}, \mathrm{THF}-\mathrm{MeOH}-\mathrm{H}_{2} \mathrm{O} \\ \text { (v:v:v= 3:1:1), rt, } 10 \mathrm{~h}(98 \%)\end{array} \longrightarrow 40: \mathrm{R}=\mathrm{Me}$

[MC-3] $\mathrm{N}$-allylmethylamine (8) $\mathrm{EDCl}, \mathrm{HOBt}$, DMAP, $\mathrm{CH}_{2} \mathrm{Cl}_{2}$, rt, $12 \mathrm{~h}$;

separation<smiles>C=CCN(C)C(=O)[C@H](C)CC(C)CC[C@H](C)CC(O)C(C)(C)C</smiles>

42a $(12 \%)$

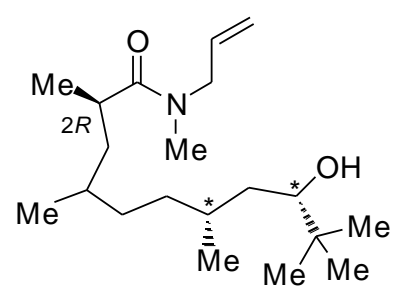

42 (78\%; mixture)

\footnotetext{
[MC-4] acryloyl chloride (9) i- $\mathrm{Pr}_{2} \mathrm{NEt}$, DMAP, $\mathrm{CH}_{2} \mathrm{Cl}_{2}$ $0{ }^{\circ} \mathrm{C}$ to $\mathrm{rt}, 10 \mathrm{~h}(87 \%)$<smiles>C=CCN(C)C(=O)[C@H](C)CC(C)CCC(C)CC(OC(=O)C=C)C(C)(C)C</smiles><smiles>CC(C)CC[C@H](C)CC(OC(=O)/C=C/C=N/C(=O)C(C)C)C(C)(C)C</smiles>

43a

column, indicating a possibility that they would be two conformational isomers of $\mathbf{4 4 a}$.

The RCM product was then subjected to alkene isomerization using $20 \mathrm{~mol} \%$ 
$\mathrm{RuH}\left(\mathrm{PPh}_{3}\right)_{3}(\mathrm{CO}) \mathrm{Cl}$ at $110{ }^{\circ} \mathrm{C}$ in $\mathrm{PhMe}$ for $24 \mathrm{~h}$ to furnish the laingolide diastereomer $1 \mathbf{a}$ in $65 \%$ isolated yield for the 2 steps from $43 \mathbf{a}$. We were pleased to note that $44 \mathbf{a}$ underwent complete alkene isomerization to afford 1a which appeared again as two related components in both ${ }^{1} \mathrm{H}$ and ${ }^{13} \mathrm{C}$ NMR spectra in a ratio of 66:34. The vinyl proton at $\mathrm{C} 14$ was found at $6.73(\mathrm{~d}, J=14.0 \mathrm{~Hz})$ and $7.62(\mathrm{~d}, J=14.4 \mathrm{~Hz}) \mathrm{ppm}$, respectively, for the major and minor components of 1a, conforming both being the (E)-enamides. The remarkably downfield vinyl proton at $\mathrm{C} 14$ is unique and has not been reported for palmyrolide A and laingolides as well as their analogues. ${ }^{8-11,13-16}$ Further study might be necessary to confirm the conformational behavior of $\mathbf{1 a}$ in different solvents and temperatures.

As shown in Scheme 12, the three diastereomers of the hydroxy amides in the mixture 42 were acylated with acryloyl chloride (9) to form the seco diene $\mathbf{4 3}$ in $90 \%$ yield. The RCM reaction within $\mathbf{4 3}$ was carried out in the same manner as $43 \mathbf{a}$ to afford the separable conjugated macrolactone $\mathbf{4 4 b}$ and the mixture 44 of two other diastereomers. Alkene isomerization of $\mathbf{4 4 b}$ and $\mathbf{4 4}$ produced, respectively, the laingolide diastereomer 1b (40\% yield from $\mathbf{4 3}$ ) and 1c/1d (56\% combined yield from $\mathbf{4 3}$ ), which could be separated over silica gel column to afford pure 1c and 1d. Therefore, four laingolide diastereomers $\mathbf{1 a}-\mathbf{1 d}$ were synthesized from $\mathrm{rac}-\mathbf{2 8}$ in one sequence in the manner as illustrated in Figure 5. The ${ }^{1} \mathrm{H} /{ }^{13} \mathrm{C}$ NMR and specific rotation data of $\mathbf{1 b}-\mathbf{1 d}$ are listed in Tables 4-6.

We analyzed the ${ }^{1} \mathrm{H}$ NMR spectra of the four structurally determined laingolide A diastereomers $\mathbf{2 a}-\mathbf{2 d}$ and noted the structural correlation with the chemical shifts of C9-H and C14-H (Table 7). For the C14 vinyl proton, high-field signals (6.76 and 6.74 ppm) were recorded for $\mathbf{2 a}$ an $\mathbf{2 d}$ possessing 2,7-syn-Me/Me relationship as compared to downfield signals (7.09 and $7.02 \mathrm{ppm}$ ) observed for $\mathbf{2 b}$ and $\mathbf{2 c}$ possessing 2,7-anti-Me/Me relationship. On the other hand, for the $\mathrm{C} 9$ proton, high-field signals (4.82 and $4.86 \mathrm{ppm}$ ) were recorded for $\mathbf{2 c}$ an $\mathbf{2 d}$ possessing 7,9-syn-Me/t-Bu relationship as compared to downfield signals (4.95 and $4.92 \mathrm{ppm}$ ) observed for $\mathbf{2 a}$ an 2b possessing 7,9-anti-Me/t-Bu relationship. 
Scheme 12. Synthesis of laingolide diastereomers $\mathbf{1 c}-\mathbf{1 d}$ from $\mathrm{rac}-\mathbf{2 8} \mathbf{8}^{35}$<smiles>C=CCN(C(=O)C(C)CC(C)CC(C)(O)C(C)(C)C)[N+](=O)O</smiles>

42 (mixture)
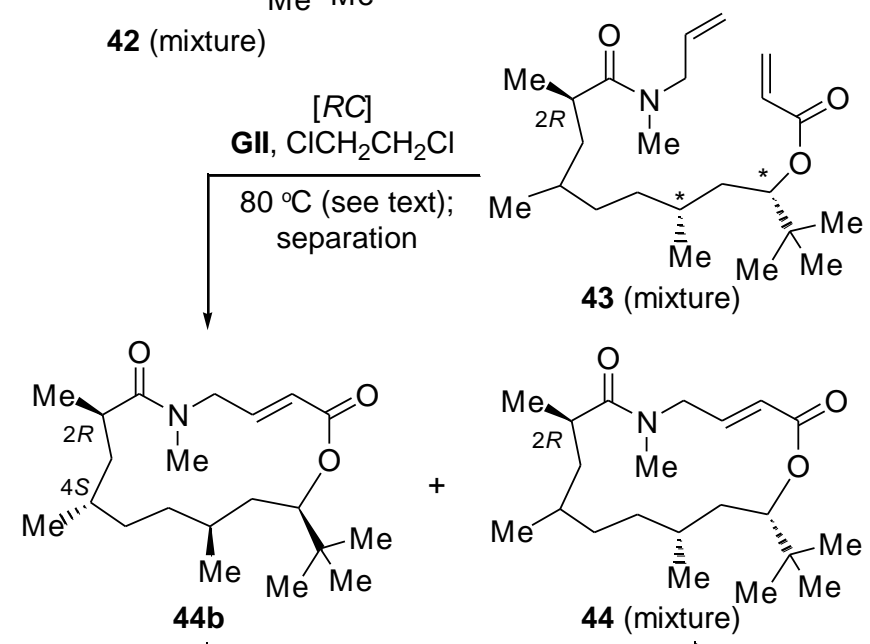

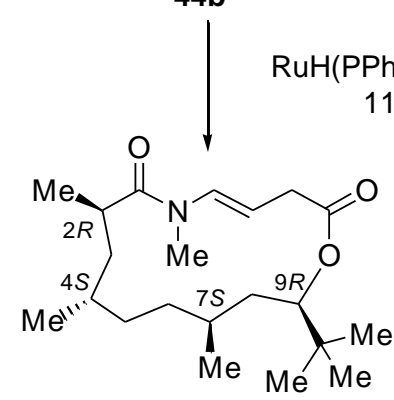

1b (40\% from 43 )

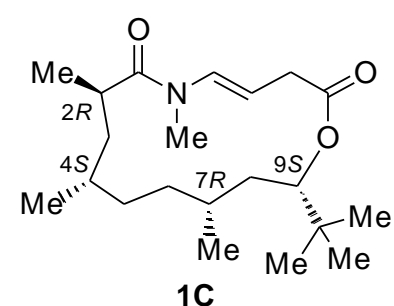

44 (mixture) 
Table 4. Comparison of ${ }^{1} \mathrm{H}$ NMR data of naturally occurring laingolide and synthetic diastereomers 1a-1d

\begin{tabular}{|c|c|c|c|c|c|}
\hline Position $^{a}$ & $\mathbf{1}^{b}$ & $1 a^{c, d}$ & $\mathbf{1 b}^{c}$ & $1 c^{c}$ & $\mathbf{1 d}^{c}$ \\
\hline 1 & - & - & - & - & - \\
\hline 2 & $\begin{array}{l}2.81, \text { ddd }(6.7 \\
6.7,3.5)\end{array}$ & $2.85-2.71, \mathrm{~m}$ & $2.94-2.89, \mathrm{~m}$ & $\begin{array}{l}2.95, \text { dd }(11.2, \\
10.4)\end{array}$ & 2.82 , br s \\
\hline $3 a$ & $1.63, \mathrm{~m}$ & $1.65-0.90, \mathrm{~m}$ & $1.71-1.60, \mathrm{~m}$ & $\begin{array}{l}\text { 1.81, dd (10.4, } \\
10.4)\end{array}$ & $1.67-1.53, \mathrm{~m}$ \\
\hline $3 b$ & $1.05, \mathrm{~m}$ & $1.65-0.90, \mathrm{~m}$ & $1.30-1.10, \mathrm{~m}$ & $1.09-0.93, \mathrm{~m}$ & $1.31-0.98, \mathrm{~m}$ \\
\hline $4 a$ & $1.58, \mathrm{~m}$ & $1.65-0.90, \mathrm{~m}$ & $1.45-1.37, \mathrm{~m}$ & $1.26-1.10, \mathrm{~m}$ & $1.67-1.53, \mathrm{~m}$ \\
\hline $5 \mathrm{a}$ & $1.26, \mathrm{~m}$ & $1.65-0.90, \mathrm{~m}$ & $1.30-1.10, \mathrm{~m}$ & $1.26-1.10, \mathrm{~m}$ & $1.31-0.98, \mathrm{~m}$ \\
\hline $5 b$ & $1.13, \mathrm{~m}$ & $1.65-0.90, \mathrm{~m}$ & $1.30-1.10, \mathrm{~m}$ & $1.09-0.93, \mathrm{~m}$ & $1.31-0.98, \mathrm{~m}$ \\
\hline $6 a$ & $1.26, \mathrm{~m}$ & $1.65-0.90, \mathrm{~m}$ & $1.30-1.10, \mathrm{~m}$ & $1.26-1.10, \mathrm{~m}$ & $1.31-0.98, \mathrm{~m}$ \\
\hline $6 b$ & $1.02, \mathrm{~m}$ & $1.65-0.90, \mathrm{~m}$ & $1.02-0.95, \mathrm{~m}$ & $1.09-0.93, \mathrm{~m}$ & $1.31-0.98, \mathrm{~m}$ \\
\hline 7 & $1.18, \mathrm{~m}$ & $1.65-0.90, \mathrm{~m}$ & $1.30-1.10, \mathrm{~m}$ & $1.26-1.10, \mathrm{~m}$ & $1.31-0.98, \mathrm{~m}$ \\
\hline $8 \mathrm{a}$ & $1.61, \mathrm{~m}$ & $1.65-0.90, \mathrm{~m}$ & $1.71-1.60, \mathrm{~m}$ & $\begin{array}{l}\text { 1.59, dd (10.4, } \\
10.4)\end{array}$ & $1.67-1.53, \mathrm{~m}$ \\
\hline $8 b$ & $1.05, \mathrm{~m}$ & $1.65-0.90, \mathrm{~m}$ & $1.30-1.10, \mathrm{~m}$ & $1.09-0.93, \mathrm{~m}$ & $1.31-0.98, \mathrm{~m}$ \\
\hline 9 & $\begin{array}{l}\text { 4.79, dd (11.4, } \\
1.8)\end{array}$ & $4.72, \mathrm{~d}(10.8)$ & $4.83, \mathrm{~d}(10.0)$ & $4.73, \mathrm{~d}(10.8)$ & $4.80, \mathrm{~d}(12.8)$ \\
\hline $10(\mathrm{O})$ & - & - & - & - & - \\
\hline 11 & - & - & - & - & - \\
\hline $12 \mathrm{a}$ & $\begin{array}{l}3.05, \text { ddd }(13.2, \\
6.4,1.5)\end{array}$ & $\begin{array}{l}3.19, \text { ABqd (16.8, } \\
6.0)\end{array}$ & $\begin{array}{l}3.22, \mathrm{ABqd}(16.4 \\
6.4)\end{array}$ & $3.18-3.07, \mathrm{~m}$ & $3.10-3.03, \mathrm{~m}$ \\
\hline $12 b$ & $\begin{array}{l}2.95 \text {, dd (13.2, } \\
9.6)\end{array}$ & $3.10-2.99, \mathrm{~m}$ & $\begin{array}{l}\text { 3.06, ABqd (16.4, } \\
8.8)\end{array}$ & $3.07-3.00, \mathrm{~m}$ & $\begin{array}{l}\text { 2.97, ABqd (11.6, } \\
\text { 10.4) }\end{array}$ \\
\hline 13 & $\begin{array}{l}5.21, \text { ddd }(13.8, \\
9.6,6.4)\end{array}$ & $\begin{array}{l}5.18, \text { ddd }(14.4, \\
8.4,6.4)\end{array}$ & $\begin{array}{l}5.29, \text { ddd }(14.4, \\
8.8,6.4)\end{array}$ & $5.20, \mathrm{~m}$ & $5.22, \mathrm{~m}$ \\
\hline 14 & $6.90, \mathrm{~d}(13.8)$ & $6.73, \mathrm{~d}(14.0)$ & $6.81, \mathrm{~d}(13.6)$ & 7.06, d (13.6) & $6.93, \mathrm{~d}(13.6)$ \\
\hline $15(\mathrm{~N})$ & - & - & - & - & - \\
\hline 16 & $1.18,3 \mathrm{H}, \mathrm{d}(6.7)$ & $1.16,3 \mathrm{H}, \mathrm{d}(6.8)$ & $1.11,3 \mathrm{H}, \mathrm{d}(6.4)$ & $1.14,3 \mathrm{H}(6.0)$ & $1.19,3 \mathrm{H}(5.6)$ \\
\hline 17 & $0.91,3 \mathrm{H}, \mathrm{d}(6.7)$ & $0.89,3 \mathrm{H}, \mathrm{d}(6.8)$ & $0.86,3 \mathrm{H}, \mathrm{d}(6.4)$ & $0.85,3 \mathrm{H}, \mathrm{s}$ & $0.92,3 \mathrm{H}(4.0)$ \\
\hline 18 & $0.80,3 \mathrm{H}, \mathrm{d}(6.4)$ & $0.84,3 \mathrm{H}, \mathrm{d}(6.4)$ & $0.81,3 \mathrm{H}, \mathrm{d}(6.0)$ & $0.77,3 \mathrm{H}, \mathrm{s}$ & $0.81,3 \mathrm{H}(4.4)$ \\
\hline 19 & - & - & - & - & - \\
\hline 20 & $0.88,9 \mathrm{H}, \mathrm{s}$ & $0.88,9 \mathrm{H}, \mathrm{s}$ & $0.88,9 \mathrm{H}, \mathrm{s}$ & $0.89,9 \mathrm{H}, \mathrm{s}$ & $0.89,9 \mathrm{H}, \mathrm{s}$ \\
\hline 21 & $3.08,3 \mathrm{H}, \mathrm{s}$ & $3.11,3 \mathrm{H}, \mathrm{s}$ & $3.14,3 \mathrm{H}, \mathrm{s}$ & $3.10,3 \mathrm{H}, \mathrm{s}$ & $3.08,3 \mathrm{H}, \mathrm{s}$ \\
\hline
\end{tabular}

${ }^{a}$ The numbering system shown in Figure 1 is used. ${ }^{b}$ Data are taken by Braekman, Daloze, and co-workers in 1996 in ref. 8 and were recorded in $\mathrm{CDCl}_{3}$ at $600 \mathrm{MHz}^{c}$ Data were recorded in $\mathrm{CDCl}_{3}$ at $400 \mathrm{MHz}$ with reference to the residual $\mathrm{CHCl}_{3}$ peak at $\delta=7.26 \mathrm{ppm}$ and are listed in the order of chemical shift ( $\mathrm{ppm})$, number of equivalent protons (if $>1$ ), multiplicity, and coupling constants $(\mathrm{Hz})$ in parenthesis. $\mathrm{ABq}$ is designated for the geminal coupling pattern of $\mathrm{CH}_{2}$ at $\mathrm{C} 12 .{ }^{d}$ Chemical shifts for the major component are listed. 
Table 5. Comparison of ${ }^{13} \mathrm{C}$ NMR data of naturally occurring laingolide and synthetic diastereomers 1a-1d

\begin{tabular}{|c|c|c|c|c|c|c|c|c|c|}
\hline Atom $^{a}$ & $\mathbf{1}^{b}$ & $\mathbf{1 a}^{c, e}$ & $\Delta \delta^{d}$ & $\mathbf{1 b}^{c}$ & $\Delta \delta^{d}$ & $\mathbf{1 c ^ { c }}$ & $\Delta \delta^{d}$ & $\mathbf{1 d}^{c}$ & $\Delta \delta^{d}$ \\
\hline 1 & 176.3 & 176.5 & -0.2 & 176.2 & 0.1 & 175.9 & 0.4 & 176.4 & -0.1 \\
\hline 2 & 34.5 & 34.4 & 0.1 & 34.9 & -0.4 & 34.9 & -0.4 & 34.5 & 0.0 \\
\hline 3 & 40.8 & 40.2 & 0.6 & 42.5 & -1.7 & 44.1 & -3.3 & 40.8 & 0.0 \\
\hline 4 & 31.3 & 31.4 & -0.1 & 31.8 & -0.5 & 32.1 & -0.8 & 31.3 & 0.0 \\
\hline 5 & 33.7 & 32.9 & 0.8 & 33.9 & -0.2 & 33.7 & 0.0 & 33.7 & 0.0 \\
\hline 6 & 33.3 & 32.4 & 0.9 & 33.7 & -0.4 & 33.0 & 0.3 & 33.3 & 0.0 \\
\hline 7 & 28.5 & 29.5 & -1.0 & 31.1 & -2.6 & 30.4 & -1.9 & 28.5 & 0.0 \\
\hline 8 & 35.4 & 35.5 & -0.1 & 35.6 & -0.2 & 35.5 & -0.1 & 35.4 & 0.0 \\
\hline 9 & 79.1 & 80.3 & -1.2 & 81.1 & -2.0 & 79.4 & -0.3 & 79.1 & 0.0 \\
\hline $10(\mathrm{O})$ & - & - & - & - & - & - & - & - & - \\
\hline 11 & 171.7 & 171.3 & 0.4 & 171.4 & 0.3 & 171.7 & 0.0 & 171.8 & -0.1 \\
\hline 12 & 36.3 & 37.6 & -1.3 & 37.0 & -0.7 & 37.0 & -0.7 & 36.3 & 0.0 \\
\hline 13 & 104.8 & 105.9 & -1.1 & 107.2 & -2.4 & 105.2 & -0.4 & 104.9 & -0.1 \\
\hline 14 & 131.9 & 131.5 & 0.4 & 131.9 & 0.0 & 132.6 & -0.7 & 131.9 & 0.0 \\
\hline $15(\mathrm{~N})$ & - & - & - & - & - & - & - & - & - \\
\hline 16 & 18.5 & 17.5 & 1.0 & 18.4 & 0.1 & 18.9 & -0.4 & 18.5 & 0.0 \\
\hline 17 & 20.6 & 20.3 & 0.3 & 21.1 & -0.5 & 21.0 & -0.4 & 20.6 & 0.0 \\
\hline 18 & 20.6 & 19.5 & 1.1 & 20.8 & -0.2 & 20.3 & 0.3 & 20.6 & 0.0 \\
\hline 19 & 34.3 & 32.9 & 1.4 & 34.3 & 0.0 & 34.3 & 0.0 & 34.4 & -0.1 \\
\hline 20 & 25.9 & 25.9 & 0.0 & 25.9 & 0.0 & 25.9 & 0.0 & 25.9 & 0.0 \\
\hline 21 & 30.6 & 30.0 & 0.6 & 31.7 & -1.1 & 31.4 & -0.8 & 30.6 & 0.0 \\
\hline
\end{tabular}

${ }^{a}$ The numbering system shown in Figure 1 is used. ${ }^{b}$ Data are taken by Braekman, Daloze, and co-workers in 1996 in ref. 8 and were recorded in $\mathrm{CDCl}_{3}$ at $125 \mathrm{MHz}^{c}$ Data were recorded in $\mathrm{CDCl}_{3}$ at $100 \mathrm{MHz}$ with reference to the residual $\mathrm{CHCl}_{3}$ peak at $\delta=77.00 \mathrm{ppm} .{ }^{d}$ The difference in chemical shifts $(\Delta \delta$ in ppm) is calculated by $\delta$ (natural) $-\delta$ (synthetic). ${ }^{e}$ Chemical shifts for the major component are listed.

Table 6. Specific optical rotation data $[\alpha]_{\mathrm{D}}$ of laingolide diastereomers $\mathbf{1 a}-\mathbf{1 d}^{a}$

\begin{tabular}{cccc}
\hline $\mathbf{1 a}^{b}$ & $\mathbf{1 b}^{c}$ & $\mathbf{1 c}$ & $\mathbf{1 d}$ \\
\hline- & $-130.9(c 1.0)$ & $-363.6(c 1.0)$ & $-186.5(c 1.0)$ \\
\hline
\end{tabular}

${ }^{a}$ The data were recorded in $\mathrm{CHCl}_{3}$ at $24{ }^{\circ} \mathrm{C} .{ }^{b}$ Not measured. ${ }^{c}$ Recorded at $21^{\circ} \mathrm{C}$. 
Table 7. Correlation of the $\mathrm{C} 9-\mathrm{H}$ and $\mathrm{C} 14-\mathrm{H}$ chemical shifts with the $2,7-\mathrm{Me} / \mathrm{Me}$ and 4,9-/7,9-Me/t-Bu for laingolide diastereomers $\mathbf{1 a}-\mathbf{1 d}$ and laingolide A diastereomers 2a-2d. ${ }^{a}$

\begin{tabular}{lllllllll}
\hline Compound & 2a & 2b & 2c & 2d & 1a & 1b & 1c & 1d \\
\hline$\delta:$ C14-H (2,7-syn-Me/Me) & 6.76 & & & 6.74 & 6.73 & 6.81 & & \\
$\delta:$ C14-H (2,7-anti-Me/Me) & & 7.09 & 7.02 & & & & 7.06 & 6.93 \\
$\delta:$ C9-H (4,9- or 7,9-syn-Me/t-Bu) & & & 4.82 & 4.86 & 4.72 & & 4.73 & \\
$\delta:$ C9-H (4,9- or 7,9-anti-Me/t-Bu) & 4.95 & 4.92 & & & & 4.83 & & 4.80 \\
\hline
\end{tabular}

${ }^{a}$ The data are extracted from Tables 1 and 4. The 4,9-Me/t-Bu and 7,9-Me/t-Bu relationships are compared, respectively for $\mathbf{1 a}-\mathbf{1 d}$ and $\mathbf{2 a}-\mathbf{2 d}$.

On the basis of these observations, we tried to assign the structures of four synthesized laingolide diastereomers 1a-1d (Table 7). The pair having high-filed C14 vinyl proton signals (6.73 and $6.81 \mathrm{ppm}$ ) should have the 2,7-syn-Me/Me relationship as in 1a and 1d while the other pair having downfield C14 vinyl proton signals (7.06 and $6.93 \mathrm{ppm}$ ) are given the 2,7-anti-Me/Me relationship as in 1c and 1d. Since all four laingolide diastereomers $\mathbf{1 a}-\mathbf{1 d}$ feature the 7,9-syn-Me/t-Bu relationship, alternative 4,9-syn-Me/t-Bu or 4,9-anti-Me/t-Bu relationship is compared. A similar trend is found for the C9 proton, i.e. the high-field proton signals (4.72 and $4.73 \mathrm{ppm}$ ) are noted for 4,9-syn-Me/t-Bu relationship in $\mathbf{1 a}$ and $\mathbf{1 c}$ and downfield proton signals are recorded for 4,9-anti-Me/t-Bu relationship in $\mathbf{1 b}$ and $\mathbf{1 d}$. Therefore, the diastereomer $\mathbf{1 d}$ whose ${ }^{13} \mathrm{C}$ NMR data perfectly match with those of the naturally occurring laingolide should have the $(2 R, 4 R, 7 R, 9 S)$-relative configuration as given in Figure 4 . In order to confirm the above assigned structures of $\mathbf{1 c}$ and $\mathbf{1 d}$, repeated synthesis using stereochemically defined hydroxy acids $\mathbf{4 0}$ has been carried out, providing identical structures of $\mathbf{1 c}$ and 1d. The details will be disclosed in an updated version in due course.

Finally, since the optical rotation data of the naturally occurring laingolide (1) and laingolide A (2) were not reported, ${ }^{8,9}$ a direct comparison of the optical rotation data of our synthetic laingolide 1d and laingolide A $\mathbf{2 c}$ is not possible. Therefore, we take into consideration of the common biosynthetic origin of laingolides $\mathbf{1}-\mathbf{3}^{8,9,11}$ and make reference to the revised absolute configuration of laingolide B (3) in our prior work ${ }^{13}$ for assignment of absolute configuration of 1 and $\mathbf{2}$ (Figure 6). Therefore, laingolids should share the same configuration at $\mathrm{C} 2$ and $\mathrm{C} 9$ as $(2 S, 9 R)$, leading to the revised 
absolut configuration of $(2 S, 4 S, 7 S, 9 R)$ - and $(2 S, 7 S, 9 R)$ - for laingolide (1) and laingolide A (2), repectively.

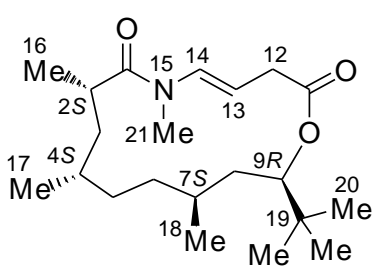

1: Laingolide (revised in this work)

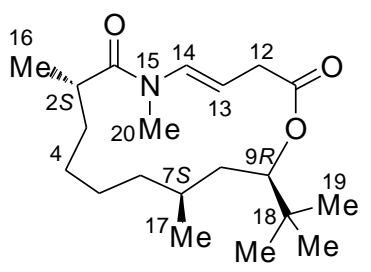

2: Laingolide A (revised in this work)

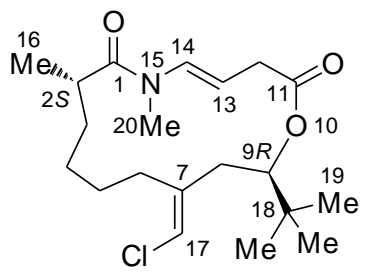

3: (+)-Laingolide $B$ (revised by Dai in 2018)

Figure 6. Revised structures of laingolides 1-3.

\section{CONCLUSIONS}

In summary, we have demonstrated a multimodule assembly (MMA) strategy for diverted total synthesis of macrocyclic natural products. Careful selection of small structural modules of orthogonal functionalities, in particular, those readily available from commercial sources could save a lot of time and manpower and enable high efficiency in accessing the target molecules. In the current work, four and eight diastereomers would be needed for decoding the stereochemical puzzles of laingolide and laingolide A. We used easily made stereo-modules 10a-10d in both racemic and enantiomerically enriched versions in combination with both "two products in one sequence" and "four products in one sequence" approaches, leading to synthesis of all four diastereomers $\mathbf{2 a}-\mathbf{2 d}$ of laingolide A and four diastereomers 1a-1d of laingolide. On the basis of our synthetic efforts, the absolut configuration of three currently known laingolides 1-3 has been established as $(2 S, 4 S, 7 S, 9 R)-\mathbf{1},{ }^{26}(2 S, 7 S, 9 R)-\mathbf{2},{ }^{24-26}$ and $(2 S, 9 R)-3^{13}$ 


\section{ACKONWLEDGMENTS}

This work is supported in part by a General Research Fund grant (601211) from the Research Grant Council, The Hong Kong Special Administrative Region, P. R. China, and the Department of Chemistry, HKUST.

\section{SUPPORTING INFORMATION}

The Supporting Information is available, including the copies of $\mathrm{PhD}$ Thesis cover page and Conference Abstracts cited in Refs. 24-26, and ${ }^{1} \mathrm{H}$ and ${ }^{13} \mathrm{C}$ NMR spectra of compounds 44a, 44b, 1a-1d, and 2a-2d.

\section{AUTHOR INFORMATION}

Corresponding Author

*E-mail: chdai@ust.hk

\section{ORCID}

Wei-Min Dai: 0000-0001-5688-7606

\section{REFERENCES AND FOOTNOTES}

1. For a series of annual reviews on marine natural products, see: Carroll, A. R.; Copp, B. R.; Davis, R. A.; Keyzers, R. A.; Prinsep, M. R. Marine Natural Products. Nat. Prod. Rep. 2020, 37, 175-223 and cited early articles.

2. (a) Simmons, T. L.; Coates, R. C.; Clark, B. R.; Engene, N.; Gonzalez, D.; Esquenazi, E.; Dorrestein, P. C.; Gerwick, W. H. Biosynthetic Origin of Natural Products Isolated from Marine Microorganism-Invertebrate Assemblages. PNAS 2008, 105, 4587-4594. (b) Riera-Romo, M.; Wilson-Savón, L.;

Hernandez-Balmaseda, I. Metabolites from Marine Microorganisms in Cancer, Immunity, and inflammation: A Critical Review. J. Pharm. Pharmacogn. Res. 2020, 8, 368-391.

3. Marine Biotechnology; Kim, S.-K. Ed.; Wiley-VCH: Weinheim, 2013.

4. For selected reviews, see: (a) Namikoshi, M.; Rinehart, K. L. Bioactive Compounds Produced by Cyanobacteria. J. Ind. Microbiol. 1996, 17, 373-384. (b)

Burja, A. M.; Banaigs, B.; Abou-Mansour, E.; Burgess, J. G.; Wright, P. C. Marine Cyanobacteria-A Prolific Source of Natural Products. Tetrahedron 2001, 57, 9347-9377. (c) Tan, L. T. Bioactive Natural Products from Marine 
Cyanobacteria for Drug Discovery. Phytochemistry 2007, 68, 954-979. (d)

Nunnery, J. K.; Mevers, E.; Gerwick, W. H. Biologically Active Secondary

Metabolites from Marine Cyanobateria. Curr. Opin. Biotech. 2010, 21, 787-793.

(e) Singh, R. K.; Tiwari, S. P.; Rai, A. K.; Mohapatra, T. M. Cyanobacteria: An

Emerging Source for Drug Discovery. J. Antibiot. 2011, 64, 401-412. (f)

Salvador-Reyes, L. A.; Luesch, H. Biological Targets and Mechanisms of Action of Natural Products from Marine Cyanobacteria. Nat. Prod. Rep. 2015, 32,

478-503. (g) Niedermeyer, T. H. J. Anti-infective Natural Products from Cyanobacteria. Planta Med. 2015, 81, 1309-1325.

5. For selected reviews, see: (a) Rastogi, R. P.; Sinha, R. P. Biotechnological and Industrial Significance of Cyanobacterial Secondary Metabolites. Biotechnol. Adv. 2009, 27, 521-539. (b) Kehr, J.-C.; Picchi, D. G.; Dittmann, E. Natural Product Biosynthesis in Cyanobateria: A Treasure Trove of Unique Enzymes. Beilstein J. Org. Chem. 2011, 7, 1622-1635. (c) Mariana G.-M;. José, L. M.-F. Chemical Diversity of Cyanobacterial Compounds: A Chemoinformatics Analysis. ACS Omega 2019, 4, 6229-6237. (d) Thuan, N. H.; An, T. T.; Shrestha, A.; Canh, N. X.; Sohng, J. K.; Dhakal, D. Recent Advances in Exploration and Biotechnological Production of Bioactive Compounds in Three Cyanobacterial Genera: Nostoc, Lyngbya, and Microcystis. Front. Chem. 2019, 7, 604. (e) Demay, J.; Bernard, C.; Reinhardt, A.; Marie, B. Natural Products from Cyanobacteria: Focus on Beneficial Activities. Mar. Drugs 2019, 17, 320. (f) Tan, L. T.; Phyo, M. Y. Marine Cyanobacteria: A Source of Lead Compounds and their Clinically-Relevant Molecular Targets. Molecules 2020, 25, 2197.

6. For a review, see: К̌ezanka, T.; Kolouchová, I.; Čejková, A.; Sigler, K. Biosynthesis and Metabolic Pathways of Pivalic Acid. Appl. Microbiol. Biotechnol. 2012, 95, 1371-1376.

7. (a) Kitanishi, K.; Cracan, V.; Banerjee, R. Engineered and Native Coenzyme $\mathrm{B}_{12}$-dependent Isovalerayl-CoA/Pivalyl-CoA Mutase. J. Biol. Chem. 2015, 290, 20466-20476. (b) Skiba, M. A.; Sikkema, A. P.; Moss, N. A.; Tran, C. L.; Sturgis, R. M.; Gerwick, L.; Gerwick, W. H.; Sherman, D. H.; Smith, J. L. A Mononuclear Iron-Dependent Methyltransferase Catalyzes Initial Steps in Assembly of the Apratoxin A Polyketide Starter Unit. ACS Chem Biol. 2017, 12, 3039-3048.

8. For the isolation and the proposed planar structure of laingolide, see: Klein, D.; Braekman, J. C.; Daloze, D.; Hoffmann, L.; Demoulin, V. Laingolide, a Novel 
15-Membered Macrolide from Lyngbya bouillonii (Cyanophyceae). Tetrahedron Lett. 1996, 37, 7519-7520.

9. For the isolation and the proposed planar structures of laingolide $\mathrm{A}$ and madangolide, see: Klein, D.; Braekman, J. C.; Daloze, D.; Hoffmann, L.; Castillo, G.; Demoulin, V. Madangolide and Laingolide A, Two Novel Macrolides from Lyngbya bouillonii (Cyanophyceae). J. Nat. Prod. 1999, 62, 934-936.

10. For the total synthesis of laingolide A diastereomers, see: Pomey, G.; Phansavath, P. Total Synthesis of Laingolide A Diastereomers. Synthesis 2015, 47, $1016-1023$.

11. For the isolation and the proposed planar structure of laingolide B, see: Matthew, S.; Salvador, L. A.; Schupp, P. J.; Paul, V. J.; Luesch, H. Cytotoxic Halogenated Macrolides and Modified Peptides from the Apratoxin-Producing Marine Cyanobacterium Lyngbya bouillonii from Guam. J. Nat. Prod. 2010, 73, $1544-1552$.

12. For a synthesis of the C1-C9 fragment of laingolide B, see: Nitelet, A.; Jouvin, K.; Evano, G. Development of a General Copper-Catalyzed Vinyl Finkelstein Reaction-Application to the Synthesis of the C1-C9 Fragment of Laingolide B. Tetrahedron 2016, 72, 5972-5987.

13. For total synthesis and structural revision of laingolide B, see: Cui, C.; Dai, W.-M. Total Synthesis of Laingolide B Stereoisomers and Assignment of Absolute Configuration. Org. Lett. 2018, 20, 3358-3361.

14. For the isolation and the proposed structure of palmyrolide A, see: Pereira, A. R.; Cao, Z.; Engene, N.; Soria-Mercado, I. E.; Murray, T. F.; Gerwick, W. H. Palmyrolide A, An Unusually Stabilized Neuroactive Macrolide from Palmyra Atoll Cyanobacteria. Org. Lett. 2010, 12, 4490-4493.

15. For the total synthesis and the structural revision of palmyrolide A, see: (a) Tello-Aburto, R.; Johnson, E. M.; Valdez, C. K.; Maio, W. A. Asymmetric Total Synthesis and Absolute Stereochemistry of the Neuroactive Marine Macrolide Palmyrolide A. Org. Lett. 2012, 14, 2150-2153. (b) Tello-Aburto, R.; Newar, T. D.; Maio, W. A. Evolution of a Protecting-Group-Free Total Synthesis: Studies en Route to the Neuroactive Marine Macrolide (-)-Palmyrolide A. J. Org. Chem. 2012, 77, 6271-6289. (c) Wadsworth, A. D.; Furkert, D. P.; Sperry, J.; Brimble, M. A. Total Synthesis of the Initially Reported and Revised Structures of the Neuroprotective Agent Palmyrolide A. Org. Lett. 2012, 14, 5374-5377. (d) 
Phikhana, S. C.; Seetharamsingh, B.; Dangat, Y. B.; Vanka, K.; Reddy, D. S. Synthesis of Palmyrolide A and Its cis-Isomer and Mechanistic Insight into trans-cis Isomerization of the Enamide Macrocycle. Chem. Commun. 2013, 49, 3342-3344. (e) Sudhakar, G.; Reddy, K. J.; Nanubolu, J. B. Total Synthesis of Palmyrolide A and Its 5,7-epi Isomers. Tetrahedron 2013, 69, 2419-2429. (f) Wadsworth, A. D.; Furkert, D. P.; Brimble, M. A. Total Synthesis of the Macrocyclic $N$-Methyl Enamides Palmyrolide A and $2 S$-Sanctolide A. J. Org. Chem. 2014, 79, 11179-11193. (g) Borra, S.; Amrutapu, S. K.; Pabbaraja, S.; Singh, Y. J. Stereoselective Total Synthesis of Palmyrolide A via Intramolecular trans N-Methyl Enamide Formation. Tetrahedron Lett. 2016, 57, 4456-4459. (h) Yadav, J. S.; Suresh, B.; Srihari, P. Expedient Synthesis of Large-Ring trans-Enamide Macrolides by CuI-Mediated Intramolecular Coupling of Vinyl Iodide with Amide: Total Synthesis of Palmyrolide A. Eur. J. Org. Chem. 2016, 2509-2513. (i) Lai, Y.; Dai, W.-M. Modular Total Synthesis of (-)-Palmyrolide $\mathrm{A}$ and (+)-(5S,7S)-Palmyrolide A via Ring-Closing Metathesis and Alkene Isomerization. Chin. J. Chem. 2021, 39, 69-74.

16. For the bioactivity of palmyrolide $\mathrm{A}$ and the synthetic analogues, see: (a) Mehrotra, S.; Duggan, B. M.; Tello-Aburto, R.; Newar, T. D.; Gerwick, W. H.; Murray, T. F.; Maio, W. A. Detailed Analysis of (-)-Palmyrolide A and Some Synthetic Derivatives as Voltage-Gated Sodium Channel Antagonists. J. Nat. Prod. 2014, 77, 2553-2560. (b) Philkhana, S. C.; Mehrotra, S.; Murray, T. F.; Reddy, S. Synthesis and Biological Evaluation of Palmyrolide A Macrocycles as Sodium Channel Blockers towards Neuroprotection. Org. Biomol. Chem. 2016, $14,8457-8473$.

17. For isolation of amantelides, see: Salvador-Reyes, L. A.; Sneed, J.; Paul, V. J.; Luesch, H. Amantelides A and B, Polyhydroxylated Macrolides with Differential Broad-Spectrum Cytotoxicity from a Guamanian Marine Cyanobacterium. J. Nat. Prod. 2015, 78, 1957-1962.

18. For isolation of bastimolide A, see: Shao, C.-L.; Linington, R. G.; Balunas, M. J.; Centeno, A.; Boudreau, P.; Zhang, C.; Engene, N.; Spadafora, C.; Mutka, T. S.; Kyle, D. E.; Gerwick, L.; Wang, C.-Y.; Gerwick, W. H. J. Org. Chem. 2015, 80, 7849-7855. 
19. For isolation of nuiapolide, see: Mori, S.; Williams, H.; Cagle, D.; Karanovich, K.; Horgen, F. D.; Smith III, R.; Watanabe, C. M. H. Mar. Drugs 2015, 13, $6274-6290$.

20. For reviews on isolation and total synthesis of apratoxins, see: (a) Tarsis, E. M.; Rastelli, E. J.; Wengryniuk, S. E.; Coltart, D. M. The Apratoxin Marine Natural Products: Isolation, Structure Determination, and Asymmetric Total Synthesis. Tetrahedron 2015, 71, 5029-5044. (b) Zhang, W.; Liu, G.; Yin, R.; Li, Y. Research Progress of Apratoxin A: A Marine Cyclic Depsipeptide with Significant Anti-cancer Activity. Chin. J. Org. Chem. 2014, 34, 475-484 (in Chinese).

21. For a recent total synthesis of revised apratoxin E and analogues, see: Mao, Z.-Y.; Si, C.-M.; Liu, Y.-W.; Dong, H.-Q.; Wei, B.-G.; Lin, G.-Q. Divergent Synthesis of Revised Apratoxin E, 30-epi-Apratoxin E, and 30S/30R-Oxoapratoxin E. J. Org. Chem. 2017, 82, 10830-10845.

22. For isolation of janadolide, see: Ogawa, H.; Iwasaki, A.; Sumimoto, S.; Kanamori, Y.; Ohno, O.; Iwatsuki, M.; Ishiyama, A.; Hokari, R.; Otoguro, K.; Omura, S.; Suenaga, K. Janadolide, a Cyclic Polyketide-Peptide Hybrid Possessing a tert-Butyl Group from an Okeania sp. Marine Cyanobacterium. J. Nat. Prod. 2016, 79, 1862-1866.

23. For the isolation and the structure of apratoxin A, see: Luesch, H.; Yoshida, W. Y.; Moore, R. E.; Paul, V. J.; Corbett, T. H. Total Structure Determination of Apratoxin A, a Potent Novel Cytotoxin from the Marine Cyanobacterium Lyngbya majuscula. J. Am. Chem. Soc. 2001, 123, 5418-5423.

24. Lai, Y. SmI ${ }_{2}$-Mediated Reductive Coupling of Acrylates/Crotonates for Diverted Total Synthesis of Designed Macrolactones, (-)-Palmyrolide A and Laingolide A. Ph.D. Dissertation, The Hong Kong University of Science and Technology, Hong Kong, China, 2015.

25. Dai, W.-M. Multimodule Assembly Strategy toward Diverted Total Synthesis of Laingolides. In Book of Abstracts, Southern China Forum on Frontiers of Synthetic Chemistry, Shenzhen, China, October 16-17, 2015; pp 20-21.

26. Dai, W.-M. Diverted Total Synthesis and Stereochemical Assignment of Laingolides. In Book of Abstracts, The 31st Academic Annual Conference of the Chinese Chemical Society, Hangzhou, China, May 5-8, 2018; Paper 10-I-008. 
27. For a review, see: Alami, M.; Peyrat, J.-F.; Brion, J.-D.

1,2-Dihalogenoalkenes:Useful Linchpins to Unsaturated Compounds via Palladium or Nickel Catalysis. Synthesis 2000, 1499-1518.

28. For examples of Suzuki-Miyaura cross-coupling reaction of trans-1,2-dichloroethylene, see: (a) Chen, X.; Millar, J. G. Preparative Scale Synthesis of Isomerically Pure $(10 E, 12 E, 14 Z)$ - and (10E,12E,14E)-Hexadeca-10,12,14-trienals, Sex Pheromone Components of Manduca sexta. Synthesis 2000, 113-118. (b) Barluenga, J.; Moriel, P.; Aznar, F.; Valdés, C. A Very Simple Synthesis of Chloroalkenes and Chlorodienes by Selective Suzuki Couplings of 1,1- and 1,2-Dichloroenthylene. Adv. Synth. Catal. 2006, 348, 347-353. Also see sequential Suzuki-Miyaura coupling of 1-chloro2-iodoethylenen: (c) Organ, M. G.; Cooper, J. T.; Rogers, L. R.; Soleymanzadeh, F.; Paul, T. Synthesis of Stereodefined Polysubstituted Olefins. 1. Sequential Intermolecular Reactions Involving Selective, Stepwise Insertion of $\operatorname{Pd}(0)$ into Allylic and Vinylic Halide Bonds. The Stereoselective Synthesis of Disubstituted Olefins. J. Org. Chem. 2000, 65, 7959-7970.

29. (a) Fürstner, A.; Seidel, G. Palladium-Catalyzed Arylation of Polar Organometallics Mediated by 9-Methoxy-9-borabicyclo[3.3.1]nonane: Suzuki Reaction of Extended Scope. Tetrahedron 1995, 51, 11165-11176. (b) Seidel, G.; Fürstner, A. Suzuki Reactions of Extended Scope: the '9-MeO-9-BBN Variant' as a Complementary Formate for Cross-Coupling. Chem. Commun. 2012, 48, 2055-2070.

30. For reviews on $B$-alkyl Suzuki-Miyaura cross-coupling reaction, see: (a) Chemler, S. R.; Trauner, D.; Danishefsky, S. J. The B-Alkyl Suzuki-Miyaura Cross-Coupling Reaction: Development, Mechanistic Study, and Applications in Natural Product Synthesis. Angew. Chem. Int. Ed. 2001, 40, 4544-4568. (b) Nicolaou, K. C.; Bulger, P. G. Sarlah, D. Palladium-Catalyzed Cross-Coupling Reactions in Total Synthesis. Angew. Chem. Int. Ed. 2005, 44, 4442-4489. (c) Kotha, S.; Mandal, K. A Retrospective on the Design and Synthesis of Novel Molecules through a Strategic Consideration of Metathesis and Suzuki-Miyaura Cross-Coupling. Chem. Asian J. 2009, 4, 354-362. (d) Suzuki, A.

Cross-Coupling Reactions of Organoboranes: An Easy Way to Construct C-C Bonds (Nobel Lecture). Angew. Chem. Int. Ed. 2011, 50, 6722-6737. (e) Jana, R.; Pathak, T. P.; Sigman, M. S. Advances in Transition Metal (Pd,Ni,Fe)-Catalyzed 
Cross-Coupling Reactions Using Alkyl-organometallics as Reaction Partners.

Chem. Rev. 2011, 111, 1417-1492. (f) Heravi, M. M.; Hashemi, E. Recent

Applications of the Suzuki Reaction in Total Synthesis. Tetrahedron, 2012, 68, 9145-9178.

31. For Aphos family of P,O-ligands, see: (a) Dai, W.-M.; Li, Y.; Zhang, Y.; Lai, K. W.; Wu, J. A Novel Class of Amide-Derived Air-Stable P,O-Ligands for Suzuki Cross-Coupling at Low Catalyst Loading. Tetrahedron Lett. 2004, 45, 1999-2001.

(b) Dai, W.-M.; Zhang, Y. A Family of Simple Amide-Derived Air-Stable P,O-Ligands for Suzuki Cross-Coupling of Unactivated Aryl Chlorides.

Tetrahedron Lett. 2005, 46, 1377-1381. (c) Dai, W.-M.; Li, Y.; Zhang, Y.; Yue, C.; Wu, J. Generation of an Aromatic Amide-Derived Phosphane (Aphos) Library by Self-Assisted Molecular Editing and Applications of Aphos in Room-Temperature Suzuki-Miyaura Reactions. Chem. Eur. J. 2008, 14, 5538-5554. (d) Sun, L.; Dai, W.-M. Determination of Absolute Configuration of 2-Methyl-2-(o-Tolyl)naphthalene and the Related Axially Chiral Biaryls.

Tetrahedron 2011, 67, 9072-9079.

32. For application of $\mathrm{Pd}(\mathrm{OAc})_{2}-$ Aphos-Y catalyst system in total synthesis, see: (a) Jin, J.; Chen, Y.; Li, Y.; Wu, J.; Dai, W.-M. Total Synthesis of Amphidinolide Y by Formation of Trisubstituted $(E)$-Double Bond via Ring-Closing Metathesis of Densely Functionalized Alkenes. Org. Lett. 2007, 9, 2585-2588. (b) Ye, N.; Dai, W.-M. An Efficient and Reliable Catalyst System Using Hemilabile Aphos for B-Alkyl Suzuki-Miyaura Cross-Coupling with Alkenyl Halides. Eur. J. Org. Chem. 2013, 831-835. (c) Wang, Y.; Dai, W.-M. Synthesis of the Conjugated Tetraene Acid Side Chain of Mycolactone E by Suzuki-Miyaura Cross-Coupling Reaction of Alkenyl Boronates. Eur. J. Org. Chem. 2014, 323-330. (d) Wu, Y.-D.; Lai, Y.; Dai, W.-M. Synthesis of Two Diastereomeric C1-C7 Acid Fragments of Amphidinolide B Using B-Alkyl Suzuki-Miyaura Cross-Coupling as the Modular Assembly Step. ChemistrySelect 2016, 1, 1022-1027. (e) Zhang, W.; Ma, H.; Li, C.-C.; Dai, W.-M. Synthesis of the C6-C8 bis-Tetrahydrofuran Fragment of the Proposed Structure of Iriomoteolide-2a via Stepwise Double $\mathrm{S}_{\mathrm{N}} 2$ Cyclization Reactions. Tetrahedron 2019, 75, 1795-1807.

33. Fürstner, A. From Total Synthesis to Diverted Total Synthesis: Case Studies in the Amphidinolide Series. Isr. J. Chem. 2011, 51, 329-345. 
34. Johnson, C. R.; Braun, M. P. A Two-Step, Three-Component Synthesis of PGE 1 : Utilization of $\alpha$-Iodoenones in $\operatorname{Pd}(0)$-Catalyzed Cross-Couplings of Organoboranes. J. Am. Chem. Soc. 1993, 115, 11014-11015.

35. The positions with * are designated for relative stereochemistry.

36. (a) Wadsworth, A. D.; Furkert, D. P.; Sperry, J.; Brimble, M. A. Total Synthesis of the Initially Reported and Revised Structures of the Neuroprotective Agent Palmyrolide A. Org. Lett. 2012, 14, 5374-5377. (b) Wadsworth, A. D.; Furkert, D. P.; Brimble, M. A. Total Synthesis of the Macrocyclic $N$-Methyl Enamides Palmyrolide A and 2S-Sanctolide A. J. Org. Chem. 2014, 79, 11179-11193.

37. Lai, Y.; Sun, L.; Sit, M. K.; Wang, Y.; Dai, W.-M. Diastereoselective Synthesis of trans-3,5-Disubstituted Dihydrofuran-2-(3H)-ones via $\mathrm{SmI}_{2}$-Mediated Reductive Coupling of 2-Alkylacrylates of $N, N$-Diisopropyl-2-hydroxybenzamide with Aldehydes. Tetrahedron 2016, 72, 664-673.

38. The enantiomerically enriched $(3 S, 5 R)-\mathbf{2 3}$ could be prepared by methylation of (5R)-5-tert-butyldihydrofuran-2(3H)-one which is available by the known method, see: Fukuzawa, S.; Seki, K.; Tatsuzawa, M.; Mutoh, K. A Facile Synthesis of Chiral $\gamma$-Butyrolactones in Extremely High Enantioselectivity Mediated by Samarium(II) Iodide. J. Am. Chem. Soc. 1997, 119, 1482-1483.

39. For examples of allylation of organomagnesium and organozinc with 2,3-dibromopropene in the presence of $\mathrm{CuCN}$ or $\mathrm{CuCl}$, see: (a) Mushti, C. S.; Kim, J.-H.; Corey, E. J. Total Synthesis of Antheliolide A. J. Am. Chem. Soc. 2006, 128, 14050-14052. (b) Betik, R.; Kotora, M. Enantioselective Synthesis of (-)-Methoxyestrone. Eur. J. Org. Chem. 2011, 3279-3282.

40. For examples of allylation of organocopper with allylic chlorides, see: (a) Kang, J.; Cho, W.; Lee, W. K. Regiospecific Alkylation of Allylic Halides with Latent $\gamma$-Functionality. J. Org. Chem. 1984, 49, 1838-1840. (b) Bäckvall, J.-E.; Sellén, M.; Grant, B. Regiocontrol in Copper-Catalyzed Grignard Reactions with Allylic Substrates. J. Am. Chem. Soc. 1990, 112, 6615-6621.

41. For a review, see: Yoshikai, N.; Nakamura, E. Mechanisms of Nucleophilic Organocopper(I) Reactions. Chem. Rev. 2012, 112, 2339-2372. 